Phonology 37 (2020) 27-63. (C) The Author(s), 2020. Published by Cambridge University Press. This is an Open Access article, distributed under the terms of the Creative Commons Attribution licence (http://creativecommons.org/licenses/by/4.0/), which permits unrestricted re-use, distribution, and reproduction in any medium, provided the original work is properly cited. doi:10.1017/S0952675720000032

\title{
Nasal consonants, sonority and syllable phonotactics: the dual nasal hypothesis*
}

Martin Krämer

UiT The Arctic University of Norway

Draga Zec

Cornell University

We investigate the phonotactic behaviour of nasal consonants in a database of over 200 languages. Our findings challenge the common classification of nasals as intermediate between obstruents and liquids on the sonority hierarchy. Instead, we propose that there are two types of nasal consonants, one group with lower sonority than liquids and one with higher sonority. We propose that these two types of nasals differ in the presence or absence of a value for the feature [ \pm continuant].

\section{Introduction}

The basic order of major segment classes in the sonority hierarchy has been by and large unchallenged since Sievers (1881: 157). In this paper we investigate the behaviour of nasal consonants in syllable phonotactics in a survey of over 200 languages. Our findings challenge the perceived wisdom that nasals occupy a relatively low position on the hierarchy, between obstruents and liquids. We find compelling evidence that there are actually two types of nasals, LOW-SONORITY NASALS and HIGHSONORITY NASALS. Languages allow either both types or just one; if both types are found they may be in complementary distribution, with low-sonority nasals in syllable onsets and high-sonority nasals in rhymes, or the language may display a contrast between the two types, in which case they are also phonetically distinct. Depending on the position of contrast

* E-mail: MARTin.KRAMER@UIT.No,DZ17@CORNELL.EDU

We are grateful to Abby Cohn, Stuart Davis, Chris Golston, Gaja Jarosz, Steve Parker, Sam Tilsen and Christian Uffmann, as well as the members of the CASTL-FISH group and the USC phonetics and phonology group, various audiences at the CUNY Phonology Forum, the Manchester Phonology Meeting and the OCP, two anonymous reviewers, the associate editor and the editors for invaluable feedback and comments. This work is part of the research carried out in the project SALT (Syllable Structure: its Acquisition, Loss, Typology), funded by the Research Council of Norway (project number 262745). 
in the syllable, it is realised as plain nasal $v s$. prenasalised stop, or as plain nasal $v s$. nasal glide (Trigo 1988). In languages that don't show a contrast, the sonority of a nasal may be determined by its position. That is, nasals could manifest low-sonority properties in the onset and high-sonority properties in the coda. This distinction need not be reflected in the phonetics, as the nasal segment can be realised as a plain nasal in both positions. In such cases, evidence about their sonority can be drawn from their combinatory properties within complex syllable constituents, and from other phonological diagnostics.

The paper is organised as follows. In $\$ 2$ we provide the theoretical background for this study. First we review the literature on sonority, the sonority hierarchy and sonority sequencing, with particular attention to the role of nasals. Then, in $\$ 2.2$, we provide the results of our cross-linguistic study, which reveals nasals to be phonotactically the most versatile consonants, being more widely attested than other consonants both in the coda and in the nucleus, i.e. as syllabic consonants. In $\$ 2.3$ we outline our proposal to account for this behaviour of nasal consonants. We propose that the two types of nasal differ in the presence $v s$. absence of the feature [continuant], and then present a cross-linguistic typology of the distribution of the two types of nasals. $\$ 3$ shows how our predictions are borne out, by supplying illustrations of predicted patterns, languages with either lowor high-sonority nasals only, languages with the two types of nasal in complementary distribution and languages with contrasting nasals. In $\$ 4$ we provide a systematic discussion of the expected and attested phonetic properties of different nasals, and $\$ 5$ discusses potential alternative explanations for our findings. $\$ 6$ concludes.

\section{The position of nasals in the sonority hierarchy}

\subsection{The sonority hierarchy and sonority sequencing}

In this section we review standard assumptions about the place of nasals in the sonority hierarchy. It is broadly assumed that sonority plays an important role in the phonotactics of segment sequencing, specifically in the internal organisation of the syllable. The distribution of segments within and across syllables is assumed to observe the sonority ranking of individual segments and segment classes. Clements (1990: 299) states this as follows: 'sequences of syllables display a quasiperiodic rise and fall in sonority, each repeating portion of which may be termed a SONORITY CYCLE'.

Sonority is standardly represented as a scale, with segments ordered from the most sonorous at one end to the least sonorous at the other. There is no single sonority scale generally agreed upon in the literature (for an overview, see Parker 2002). The scales that have been proposed differ in granularity, as well as in the relative ordering of segments. However, all respect the obstruent-sonorant divide, with stops and fricatives grouped against nasals and liquids. Some of the variation is illustrated in the four sample scales in Table I. 
Nasal consonants, sonority and syllable phonotactics

\begin{tabular}{|c|c|c|c|c|}
\hline & $\begin{array}{l}\text { (a) } \\
\text { Clements }\end{array}$ & $\begin{array}{l}\text { (b) } \\
\text { Kiparsky }\end{array}$ & $\begin{array}{l}\text { (c) } \\
\text { Selkirk }\end{array}$ & $\begin{array}{l}\text { (d) } \\
\text { Jespersen }\end{array}$ \\
\hline vowels & vowels & $\begin{array}{l}\text { low vowels } \\
\text { mid vowels } \\
\text { high vowels }\end{array}$ & $\begin{array}{l}\text { low vowels } \\
\text { mid vowels } \\
\text { high vowels }\end{array}$ & $\begin{array}{l}\text { low vowels } \\
\text { mid vowels } \\
\text { high vowels }\end{array}$ \\
\hline \multirow{3}{*}{ sonorants } & glides & glides & glides & \\
\hline & liquids & $\begin{array}{l}\text { rhotics } \\
\text { laterals }\end{array}$ & $\begin{array}{l}\text { rhotics } \\
\text { laterals }\end{array}$ & rhotics \\
\hline & nasals & nasals & nasals & $\begin{array}{l}\text { laterals } \\
\text { nasals }\end{array}$ \\
\hline obstruents & obstruents & $\begin{array}{l}\text { fricatives } \\
\text { stops }\end{array}$ & $\begin{array}{l}/ \mathrm{s} / \\
\text { voiced fricatives } \\
\text { voiceless fricatives } \\
\text { voiced stops } \\
\text { voiceless stops }\end{array}$ & $\begin{array}{l}\text { voiced fricatives } \\
\text { voiced stops } \\
\text { voiceless fricatives } \\
\text { voiceless stops }\end{array}$ \\
\hline
\end{tabular}

Table I

Sample sonority scales.

Our focus here is on the place of nasals in the various versions of sonority scales. We have found no proposals in which nasals are more sonorous than liquids. In most scales, liquids exceed nasals in sonority, as in (a)-(c). What seems to be a departure from this standard assumption is the scale in (d), with laterals and nasals placed in the same slot, both outranked by rhotics. However, Jespersen lists laterals above nasals, which suggests their higher sonority. This is echoed in Heffner (1950), where rhotics outrank both laterals and nasals, which jointly constitute a single sonority class. ${ }^{1}$

Scales such as those in Table I have been operationalised to account for segment sequencing. It has been noted, for example by de Saussure (1916), that the ordering between vowels and consonants, as well as within the class of consonants, is by and large predictable from sonority. According to Sievers (1881), one of the earliest works that addresses the organisational role of sonority, 'possible syllables are mla, mra and alm, arm but not lma, rma or $a m l$, $a m r$ ' (1881: 157; our translation). Nasals precede liquids in the onset, where sonority is on the rise, and follow them in the coda, where sonority falls. The view that nasals are less sonorous than liquids for the purposes of prenuclear and postnuclear segment sequencing persists in subsequent works, including Kiparsky (1979), Steriade (1982), Selkirk (1984) and Clements (1990), as well as Vennemann (1972) and Hooper (1976), who employ a strength hierarchy, which is the sonority hierarchy in reverse. This same ranking is also assumed to be responsible for

1 Some of the sonority scales involve sonority distinctions within the class of nasals, as for example in Rose (2000), where $/ \mathrm{n} /$ is more sonorous than $/ \mathrm{m} /$. This, however, is not part of our immediate focus. 
optimising the sonority slope between peaks and margins. If liquids are more sonorous than nasals, obstruent-liquid (OL) onsets will exhibit a greater sonority difference than obstruent-nasal $(\mathrm{ON})$ onsets, and as such, are preferred. As a result, ON imply OL, but not vice versa. This is noted by Hooper (1976), Greenberg (1978), Clements (1990) and Baertsch (2002), among many others.

In addition to such syntagmatic sonority generalisations, there are also sonority generalisations of a paradigmatic nature, i.e. those that state sonority thresholds in specific syllabic positions. First, the sonority scale is responsible for determining language-specific thresholds for selecting syllable peaks. Scales proposed for this purpose generally rank liquids as more sonorous than nasals, with the implicational relation that, if nasals can occur as syllable nuclei, so can liquids (Dell \& Elmedlaoui 1985, 1988, Zec 1988, 1995, 2007, Clements 1990, Prince \& Smolensky 1993). However, Bloomfield (1933: 121-122) does not distinguish between liquids and nasals in his discussion of syllabicity in English, treating them as a single class of sonants. This same perspective is expounded in Sievers (1881: 157), where nasals and liquids are equally sonorous for determining syllable nuclei, but not for determining syllable margins.

This same sonority scale, with nasals less sonorous than liquids, is assumed to be responsible for characterising the preference for highsonority codas. According to Vennemann (1972), Hooper (1976) and Clements (1990), liquids are preferred over nasals in this position, again with the implicational relation that, if a language allows coda nasals, it should also allow coda liquids. The preference for high-sonority segments as weight-bearing codas is also captured with this ranking. According to Zec (1988, 1995) and Morén (1999), the weight of coda consonants is governed by a sonority hierarchy in which liquids are ranked above nasals. Again, weight-bearing nasals imply weight-bearing liquids. Finally, the preference for low-sonority segments in the onset means that nasals are preferred to liquids. As argued in Hankamer \& Aissen (1974), Prince \& Smolensky (1993) and Smith (2007), liquids, as the most sonorous among consonants, may be excluded from the onset position; again, nasals are considered to be less sonorous.

There are only a very few departures from the general conjecture that nasals are less sonorous than liquids. As shown in Table Id above, Jespersen (1904) treats nasals and laterals as equally sonorous, or at least almost so, and both as less sonorous than rhotics. But the perspective presented above is prevalent. In fact, Clements (1990) proposes a unified account of the effect of sonority on the organisation of the syllable, based on the sonority scale shown in Table Ia, thus making a strong claim that nasals are less sonorous than liquids in all aspects of syllabic organisation.

\subsection{Some odd characteristics of nasals in syllable phonotactics}

We compiled a language database, consisting of 218 languages from 56 families at the time of writing, with basic information on segment 
inventory and phonotactic restrictions for each language. ${ }^{2}$ All 218 languages in the database have closed syllables.

When examining coda inventories, we considered the major manner classes liquid (i.e. rhotics and laterals; henceforth L), nasal (N), fricative (F) and oral stop (or plosive; henceforth $\mathrm{P}$ ). We ignored glides, since they are often not treated as coda consonants, but rather considered to be parts of diphthongs. Taking them into consideration would have required making assumptions about their affiliation with the nucleus or coda, and further checking details such as whether coda consonants are allowed after diphthongs and whether such configurations could instead be complex codas. This was not always possible, given the limited coverage of some of the sources. Laryngeal stops and fricatives were also ignored, since their potential status as glides or placeless segments is controversial. Excluding glides also allows us to have 'liquid' as a class, rather than 'approximant'. The latter would have included a broader range of segments than just laterals and rhotics, which are the segments we subsume under 'liquid'. Also, a class of approximants would have excluded some phonetic realisations of rhotics that we do include in the liquid class, i.e. taps and trills. Despite the more fine-grained distributional conditions for taps and trills in languages like Spanish, which has rhotics of both types, the realisation of rhotics as taps, trills or approximants does not seem to affect their phonotactic behaviour (Wiese 2001, 2003). See also Ladefoged \& Maddieson (1996: 243) on the close relation between laterals and rhotics.

Crucial for us are restricted coda inventories, i.e. those that lack one or more major manner classes. If nasals occur in the coda in a language lacking liquids, we treated this as a case of all sonorants occurring in the coda, and if stops occur in the coda in a language lacking fricatives, we assumed that all obstruents occur in the coda. Furthermore, we divided codas into word-final and word-medial, since there is a substantial literature arguing that word-final consonants are not syllabified as codas, but rather as onsets of defective syllables, or adjuncts to syllables, feet, prosodic words or the like (e.g. Piggott 1999, though cf. Krämer 2003). We thus ended up with 120 languages with restricted inventories in wordmedial position and 97 in word-final position. In languages lacking one or more major manner classes in the coda, we found that nasals are much more common than the other three classes.

The high frequency of occurrence of nasals in codas is shown in Fig. 1. The bars on the left show the percentage of restricted coda inventories that allow nasals as well as some other class or classes. Languages like Manam (Lichtenberk 1983), which allow no consonants in the coda other than nasals, amount to $30 \%$ word-medially and $24.7 \%$ word-finally. The two bars on the right show the frequency of nasals in restricted coda inventories altogether, amounting to $97.5 \%$ and $97.9 \%$ respectively. Thus there are hardly any languages in our corpus whose coda inventories do not allow nasals.

2 The database is available as online supplementary materials at https://doi.org/10. $1017 /$ S0952675720000032. 


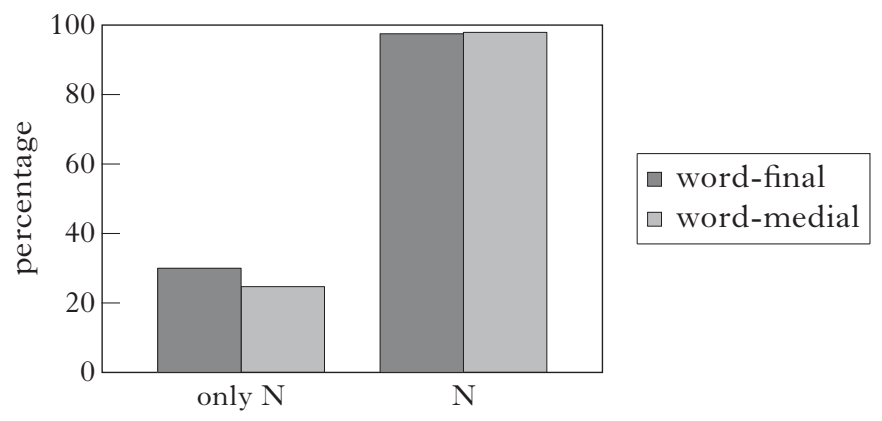

Figure 1

Systems in which nasals can occur in the coda: (left) as the only consonant class; (right) along with other consonant classes.

Figure 2 compares nasals with the other three classes in terms of absolute numbers, and further illustrates the dominant presence of nasals in restricted inventories. Of the languages with only one class in the coda (39 word-medial and 26 word-final), 36 and 24 respectively have only nasals, and none have only liquids. In light of claims in the literature that sonority correlates with coda well-formedness, the absence of liquids is particularly striking. If sonority determined coda well-formedness, the higher-sonority liquids should have behaved in the same way as nasals. The occurrence of languages that allow only fricatives or only stops in the coda is also unexpected.

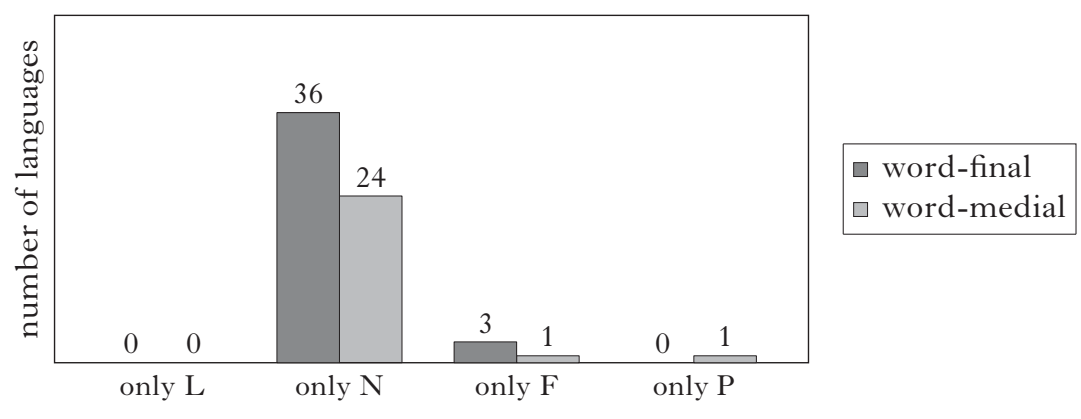

Figure 2

Number of systems in which only one consonant class can occur in the coda.

Under a strong version of Clements' (1990) claim that sonority is maximised in the coda, we would expect an implicational relation, with every lower-sonority segment class presupposing the presence of the higher- 
sonority classes. Thus one would expect some languages to allow only liquids, others to allow liquids and nasals, and yet others to allow liquids, nasals and fricatives, but none to allow only nasals.

The claim that high sonority is favoured in the coda is borne out, however, if we compare sonorants (i.e. liquids and nasals together) with obstruents. Languages with liquids and nasals in the coda are far more common than languages with any other combination of two of the four consonant classes in the coda, as shown in Fig. 3. A striking result here, however, is the high frequency of systems that allow nasals and stops.

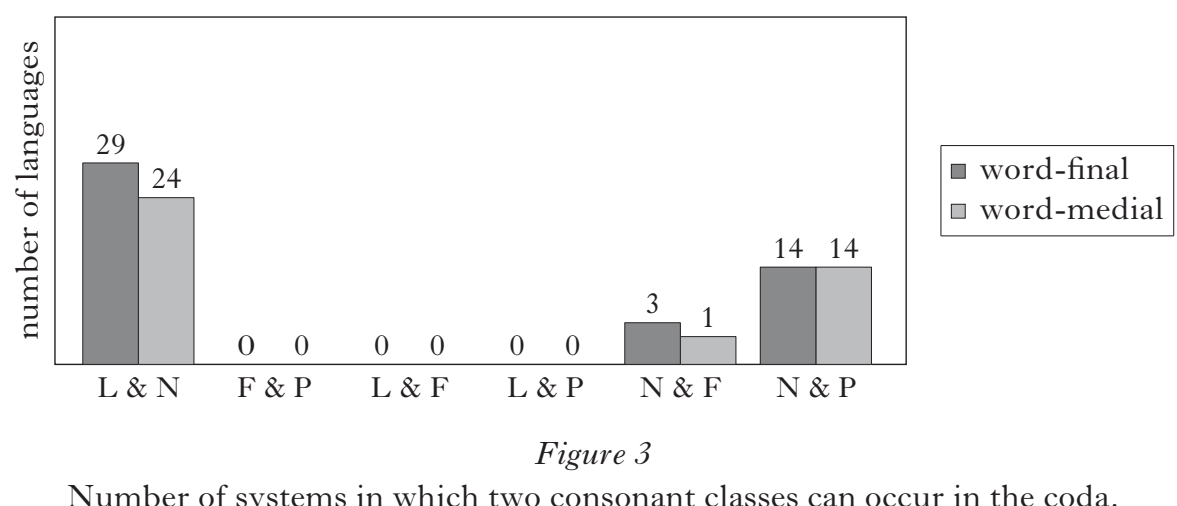

Number of systems in which two consonant classes can occur in the coda.

Another syllabic constituent usually claimed to be subject to sonority restrictions is the syllable nucleus. Again, sonority is correlated with well-formedness. The more sonorous a segment, the better it is suited as a syllable nucleus. This claim is challenged by Bell (1978) and Cooper (2013), however. In Bell's set of 85 languages, more languages have syllabic nasals than liquids, while Cooper compiled information on 131 languages, of which 77 allow only nasals as syllabic consonants, five fricatives, four rhotics and only one laterals. Gordon (2016: 110) examined 100 languages from Dryer \& Haspelmath (2013) for syllabic consonants. Only 13 of these allow syllabic consonants at all, and ten of these have only nasals in the nucleus.

Accordingly, we investigated which consonant classes occur most frequently as syllabic in our database. The results are shown in Fig. 4, and corroborate Bell's, Cooper's and Gordon's findings on the predominance of nasals. Of the 88 languages with syllabic consonants, a total of 81 have syllabic nasals, while only 26 have syllabic liquids, six have fricatives and one has stops. 58 languages allow only nasals as syllable nuclei, while five allow only liquids, and two have only fricatives, the alveolar spirant in both cases. Finally, only three of the languages with syllabic nasals do not have liquids, and the languages that allow only liquids in the nucleus all have nasals. 
(a)

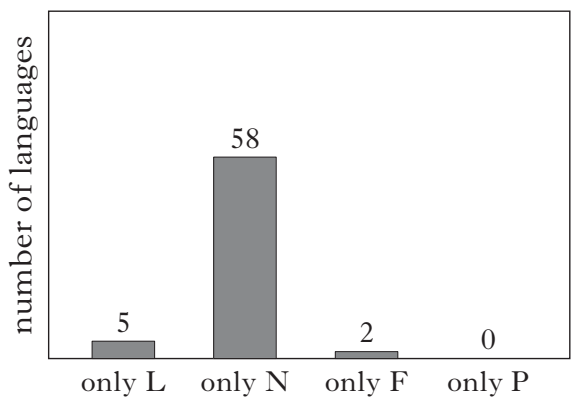

(b)

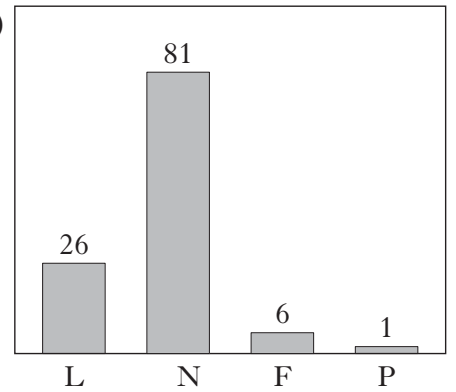

Figure 4

Number of systems with syllabic consonants: (a) in which only one consonant class can be syllabic; (b) in which more than one consonant class can be syllabic.

These results go against the predictions of the sonority hierarchy (see e.g. Clements 1990). ${ }^{3}$ Frequency should align with the sonority scale, and there should optimally be the implicational relation between different types of syllabic consonants in (1).

(1)

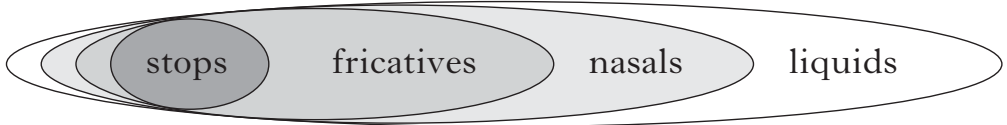

However, in $\mathbf{5 5}$ of the languages that also have liquids, only nasals can be syllabic. Again, the predictions of the sonority hierarchy only hold for a comparison of sonorants with obstruents. In particular, languages with syllabic obstruents also have syllabic sonorants, but not vice versa.

Evidence for the relatively low position of nasals on the sonority hierarchy comes, among other things, from restrictions on complex onsets (see \$2.1). Typologically, nasals are more marked in the second position $\left(\mathrm{C}_{2}\right)$ of complex onsets than liquids (e.g. Greenberg 1978, Berent et al. 2007, Zec 2007). This is compatible with the Sonority Distance Principle (Sievers 1881, Jespersen 1904, Saussure 1916, Hooper 1976, Kiparsky 1979, Steriade 1982, Selkirk 1984). Thus, in languages that require a minimal sonority difference within a complex onset, liquids are allowed in $\mathrm{C}_{2}$ position, but the less sonorous nasals are not. The information in our database on this aspect of syllable phonotactics is largely consistent with what has been found in the literature.

3 Clements was aware of Bell's (1978) study and the problem resulting for the sonority hierarchy, but despite his apparent unease with this situation, did not consider changing the hierarchy or the principles to account for this. He instead refers to Bell's speculation that there might be a connection between unstressed vowel reduction and the choice of syllabic consonant. 
While our data show nasals to be at least highly compatible with high sonority, there is also evidence that shows that nasals are closely related to the lowest-sonority class, the stops. Central Rotokas has only six consonants, $/ \mathrm{p} \mathrm{t} \mathrm{k} \mathrm{b} \mathrm{d} \mathrm{g/,} \mathrm{with} \mathrm{free} \mathrm{variation} \mathrm{in} \mathrm{the} \mathrm{voiced} \mathrm{series} \mathrm{between} \mathrm{nasals,}$ prenasalised voiced stops and voiced stops (Firchow \& Firchow 1969, Robinson 2006). The nasal stops in Aita Rotokas (which also has voiced and voiceless stops) 'systematically correspond to voiced stops in Central Rotokas' (Robinson 2006: 207). In Maxakalí (Gudschinsky et al. 1970), which has the consonant inventory $/ \mathrm{p} \mathrm{t} \mathrm{c} \mathrm{k} \mathrm{m} \mathrm{n} \mathrm{n} \mathrm{y} /$, underlying nasals can be realised as plain nasals, prenasalised stops, oral stops with nasalisation of the following vowel or glides with nasalisation of the adjacent vowel, as illustrated by [nãn, ngãj, gãj] 'angry'. There is often a historical connection between nasals and stops. For example, in Lushootseed, nasals developed historically into voiced stops (Kinkade 1985, Urbanczyk 2001). While Lushootseed is one of the very few languages without nasal consonants in their core phonology, in certain special styles nasals replace voiced stops, 'return[ing] to an earlier manner of articulation' (Hess 1982: 92-93).

The tendency of nasality to co-occur with stops and vowels, but not with the classes in between, i.e. fricatives and liquids, has been observed by a range of scholars (see especially Cohn 1993). Trigo (1988) distinguishes between nasal stops and nasal glides, i.e. between nasals that are consonantal and those that are closer to vowels, and Trigo (1993) proposes the redundancy rule in (2), which fills in the feature [nasal] in non-continuant sonorants.

(2) $[+$ son, - cont $] \rightarrow[+$ nas $]$

Rice \& Avery (1989) posit a feature-geometric difference between nasals that trigger voicing assimilation in obstruents and those that do not (and further distinguish between obstruents that are targets of such assimilation and those that are not). Piggott (1992: 34) accounts for two types of nasal harmony by proposing two distinct positions for the feature [nasal] within the feature geometry. This constitutes a basis for distinguishing between 'languages that manifest the nasal-oral contrast within the class of [+consonantal] segments and those in which a similar contrast is restricted to vowels or to sonorant consonants'. Botma (2004) makes a similar observation, finding that nasals pattern with obstruents or with vowels, spreading voicing to the former and nasality to the latter. That is, he distinguishes two types of nasals according to whether they cause postnasal voicing or nasal harmony. In a cross-linguistic study of prenasalised stops, Durvasula (2009) also concludes that there must be two types: one is basically a nasal and the other a voiced stop. Like Botma, he bases his argument on the observation that one type spreads nasality while the other spreads voicing. As we have just seen, historically voiced stops can be reanalysed as nasals, and vice versa, and prenasalised stops are often positional or free variants of nasals. 
We have shown in this section that in our database nasals are very frequent in coda position, often to the exclusion of all other segments, even those which are more sonorous. Nasals are also highly amenable to being syllabic, outnumbering liquids in this position. On the other hand, they often pattern with voiced stops, both synchronically and diachronically.

In the following section we will propose that nasals are not one class of segments on the sonority scale, but two.

\subsection{Two types of nasal}

As we saw in $\$ 2.1$, it has generally been assumed that nasals are relatively low on the sonority hierarchy, as shown again in (3a). To account for the peculiar cross-linguistic behaviour of nasals observed in the previous section, we propose that nasals occupy two positions on the sonority scale. As indicated in (3b), high-sonority nasals are higher on the sonority hierarchy than liquids, and low-sonority nasals lower.

(3) a. obstruents $<$ nasals $<$ liquids $<$ vowels

b. obstruents $<$ low nasals $<$ liquids $<$ high nasals $<$ vowels

We further assume that high- and low-sonority nasals differ in terms of their feature specification. The levels of the sonority scale can be defined in terms of features, by successively splitting up the segment inventory. For example, the tree in (4), based on Giegerich (1992: 61), specifies nasals as [+sonorant, -continuant] segments, setting them apart from liquids, which are [+continuant].

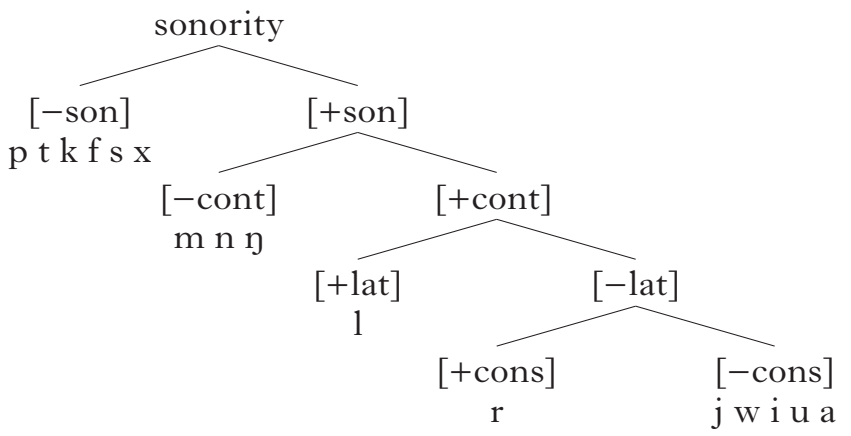

In at least two other proposals that use features to characterise the sonority hierarchy, nasals and liquids are distinguished by invoking a stricture feature: [continuant] in Basbøll (1977), and [approximant] in Clements (1990). However, this solution is inconsistent with Mielke's $(2005,2008)$ finding that both liquids and nasals can pattern as either [+continuant] or [-continuant]. A plausible alternative, which we adopt here, is proposed in Lekach (1979), where the feature [nasal] is responsible for the split between nasals and liquids, and continuancy is specified independently within each of the classes. 
We propose that the dual patterning of nasals documented in our database depends crucially on the feature [continuant], in particular on whether this feature is specified in their representation. While other researchers have posited two classes of nasals (see §2.2), the representations they propose to capture this split differ from ours. ${ }^{4}$ In fact, closest to our perspective is Mielke's (2005) proposal. But while we agree with Mielke that nasals can be specified as either [-continuant] or [+continuant], we argue that this simple binary classification is not sufficient. Thus, in addition to low-sonority nasals, which are specified for [continuant], we also posit nasals unspecified for continuancy, i.e. high-sonority nasals; the former are more consonant-like, and the latter are more vowel-like. We further note that nasals, as featurally ambiguous segments (Mielke 2005), may pattern as either [+continuant] or [-continuant], but this difference cannot serve as a basis for distinguishing between high- and low-sonority nasals. In sum, the position of nasals below liquids on the sonority scale depends on their having a specification for [continuant]. Since high-sonority nasals are not specified for [continuant], they are, at the very least, higher on the sonority scale than laterals. This is reflected in the representations in (5), with high-sonority nasals represented as (5a), and low-sonority nasals as either (5b.i) or (5b.ii).

(5) a. High-sonority nasals

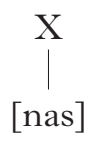

b. Low-sonority nasals

\section{i. non-continuant}

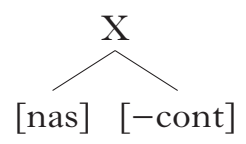

ii. continuant

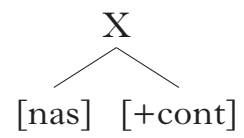

These representations capture the range of empirically attested types of nasals. The representation in (5b.i) is reserved for nasals that pattern with non-continuant segments, a type of interaction discussed in Padgett (1991) and Mielke (2005, 2008). Among nasals specified as [+continuant] (b.ii), we include those that interact with fricatives, as reported in Mielke (2005). The class of [+continuant] nasals also includes nasal fricatives (Ladefoged \& Maddieson 1996: 131-134); such nasals do not occur very often, which can be attributed to the aerodynamic challenge they pose (Ohala 1975, Shosted 2006). We will not consider them further, since their rarity clearly does not have a phonological cause, but a physiological one. Crucially, some languages use the representational choices in (5) contrastively, distinguishing between high- and low-sonority nasals in the same syllabic position. The most extreme case is Waffa, discussed in

4 Thus, a split in the class of nasals proposed in Rice \& Avery (1989) and Piggott (1992) is captured by relying on the feature-geometric representations of voicing, as well as nasality. Rice \& Avery represent one type of nasal as a bare spontaneous voicing node, and the other as spontaneous voicing node dominating [nasal]. Piggott posits a split within the class of nasals by representing one class with [nasal] dominated by the soft palate node, and the other by the spontaneous voicing node. 
Ladefoged \& Maddieson (1996: 134), which distinguishes between plain nasals, prenasalised voiced stops and nasalised fricatives (as well as plain stops and plain fricatives) in onsets, i.e. contrasting (5a), (5b.i) and (5.bii) respectively.

In sum, we consider nasals specified for continuancy to be lower on the sonority hierarchy than liquids. They can be diagnosed by their patterning, or close interactions with obstruents, either stops or fricatives. High-sonority nasals occur in languages in which the feature [continuant] is phonologically active in obstruents but not in sonorants, comparable to the laryngeal features, which in many languages are phonologically active only in obstruents. In such languages, nasals are unspecified for [continuant], patterning as high-sonority nasals, and as such are more likely to interact with sonorants than with obstruents. In the remainder of this paper, we focus on the distinction in sonority between nasals specified for [continuant] and those that are not. Since [+continuant] nasals are very rare, and not well documented (see e.g. Cohn 1993 for discussion), nasals specified for continuancy in our examples are all [-continuant].

Given these representations for nasals, sonority sequencing can be assumed to be operative in the shaping of syllables across languages, without any modification. Moreover, the strong claim that coda inventories prefer more sonorous consonants to less sonorous ones can be maintained. The higher frequency of nasals than liquids in codas can thus be attributed to the optionality of the [-continuant $]$ specification in this segment class.

Turning to how the different types of nasals match up with positions within the syllable, we posit at least three types of cases. First, we expect that some languages have only one type of nasal, with either high or low sonority, as in (6a). If a language has both high- and low-sonority nasals, then the two nasals may occupy different syllabic positions, as in (6b), with low-sonority nasals occurring in the onset and high-sonority nasals in the rhyme, or the two nasals may contrast in the same syllabic position, as in (6c). We expect onsets to prefer low-sonority nasals, and nuclei and codas to prefer high-sonority nasals. Thus we expect to find languages with low-sonority nasals in the onset and high-sonority nasals elsewhere, or no nasals outside the onset.

\section{(6) Nasal typology}

a. One type of nasal only (either low or high sonority).

b. Nasals with high or low sonority according to position.

c. High-sonority and low-sonority nasals in contrast.

We also expect to find mixed systems, in which the two types of nasals contrast in one position, e.g. the coda, and are neutralised to low sonority in the onset, or the reverse, with contrast in the onset and neutralisation to either high- or low-sonority nasals in the coda. While contrasting highsonority and low-sonority nasals occurring in the same syllabic position need to be realised in phonetically distinct ways, this is not the case 
when neutralisation is involved. If a language allows only low-sonority nasals in onsets and only high-sonority nasals in codas, they may well be realised phonetically in the same way, for example as plain nasals.

In order to establish a diagnostic for the relative sonority of nasals, we employ the criteria in Table II, which gives the patterns we expect to find in the different types of languages.

(a)

\begin{tabular}{|l|}
\hline Criteria for $\mathrm{N}>\mathrm{L}$ \\
\hline i. coda $\mathrm{N}, * \mathrm{~L}$ \\
ii. syllabic $\mathrm{N}, * \mathrm{~L}$ \\
iii. complex onset: $\mathrm{LN}$ \\
iv. complex onset: $\mathrm{ON}, * \mathrm{OL}$ \\
v. simple onset: $* \mathrm{~N}$ \\
vi. no $\mathrm{N}$ strengthening \\
\hline
\end{tabular}

(b)

\begin{tabular}{|l|}
\hline Criteria for $\mathrm{L}>\mathrm{N}$ \\
\hline i. coda $\mathrm{L}, * \mathrm{~N}$ \\
ii. syllabic $\mathrm{L}, * \mathrm{~N}$ \\
iii. complex onset: $\mathrm{NL}$ \\
iv. complex onset: $\mathrm{OL}, * \mathrm{ON}$ \\
v. simple onset: $\mathrm{L}$ \\
vi. $\mathrm{N}$ strengthening \\
\hline
\end{tabular}

\section{Table II}

Surface criteria for nasal sonority.

If a language has nasals in the coda, but not liquids and obstruents, there is reason to suspect that the language has high-sonority nasals, at least in postvocalic position (a.i). If a language with liquids has syllabic nasals, but not syllabic liquids, the nasals must be of the high-sonority type, at least when they are syllabic (a.ii). If a language has complex onsets with liquids preceding nasals, these nasals have high sonority (a.iii). In a language that displays complex onsets with obstruents followed by nasals but not liquids, the nasals are more sonorous than the liquids (a.iv). In a language that has liquids but not nasals in the onset (a.v), liquids are more sonorous than nasals. The weakest criterion is the lack of phonetic strengthening, i.e. the lack of prenasalised stops (a.vi). Not many languages have prenasalised stops, and those which do combine the feature [nasal] with the feature specification [-continuant] in these segments (b.vi). As can be seen from this comparison of (a.vi) and (b.vi), the criteria in (b) reverse those in (a). A language which allows liquids, but no other consonant class, in the coda can reasonably be suspected to have low-sonority nasals only (b.i). The presence of syllabic liquids, together with the absence of syllabic nasals, is also an indicator that a language has only low-sonority nasals (b.ii). If nasals can be followed by liquids in a complex onset, the nasals have to be less sonorous than the liquids (b.iii), unless the language displays sonority reversals in onsets (roughly, any order of consonants is possible). The same holds if a language has liquids, but not nasals, in second position in complex onsets. The nasals in this language have to have low sonority, at least in the onset (b.iv). And, if a language has nasals in the onset, but not liquids (b.v), liquids are more sonorous than nasals.

In many languages, we expect to find a combination of these criteria, i.e. a language could allow only nasals in the coda, have complex onsets with 
nasals as $\mathrm{C}_{2}$, complex onsets consisting of liquid + nasal (but not nasal + liquid), and syllabic nasals, while not allowing liquids in the nucleus. This language clearly has high-sonority nasals. It could, in addition, have prenasalised stops contrasting with plain nasals in simple onsets ((a.vi) and (b.vi)). In this case, it would have both types of nasal.

We expect certain patterns to co-occur, and others not to. For example, a language that has nasals as $\mathrm{C}_{2}$ in complex onsets, but not liquids (a.i.), and at the same time allows liquids in the coda, but not nasals (b.i), is predicted not to exist.

\section{A typology of nasal consonants}

We propose a typology of the patterning of low- and high-sonority nasals, following the criteria in Table II. The typology, given in Table III, includes four language types. For each, we list the identifying criteria, with the expected patterns sketched out in the last column.

\begin{tabular}{|c|c|c|c|}
\hline & nasal types & criteria & \\
\hline type 1 & low-sonority $\mathrm{N}$ only & $\begin{array}{l}\text { b.ii } \\
\text { b.iii } \\
\text { b.iv }\end{array}$ & $\begin{array}{l}\text { syllabic } \mathrm{L}>\mathrm{N} \\
\mathrm{NL} \text { onset } \\
\text { complex onset } \mathrm{OL}, * \mathrm{ON}\end{array}$ \\
\hline type 2 & high-sonority $\mathrm{N}$ only & a.i, a.ii & $\mathrm{N}$ only $\mathrm{C}$ in nucleus and coda \\
\hline type 3 & $\begin{array}{l}\text { low-sonority } \mathrm{N} \text { in } \\
\text { onsets, high-sonority } \\
\text { elsewhere }\end{array}$ & $\begin{array}{l}\text { a.i, a.ii, b.iii, } \\
\quad \text { b.iv } \\
\text { a.i } \\
\text { b.v }\end{array}$ & $\begin{array}{l}\text { only } \mathrm{N} \text { in coda, only } \mathrm{N} \text { in nucleus, } \\
\text { no } \mathrm{N} \text { in complex onset } \\
\mathrm{N} \text { only coda, } \mathrm{N} \text { moraic } \\
\text { onset } \mathrm{N}, * \mathrm{~L}\end{array}$ \\
\hline type 4 & $\begin{array}{l}\text { low- and high- } \\
\text { sonority } \mathrm{N} \text { in contrast }\end{array}$ & & $\begin{array}{l}\text { different Ns in onset, nucleus and } \\
\text { coda }\end{array}$ \\
\hline
\end{tabular}

Table III

Dual nasal typology with classification criteria.

\subsection{Low-sonority nasals only}

Here we report on languages in which nasals are less sonorous than liquids across the board, i.e. in each syllabic position. This pattern, standardly assumed in the literature, is illustrated here with Imdlawn Tashlhiyt Berber, Bulgarian and English.

3.1.1 Imdlawn Tashlhiyt Berber (Afro-Asiatic, Berber). Imdlawn Tashlhiyt Berber is a language in which any consonant can be syllabic, as detailed in Dell \& Elmedlaoui $(1985,1988)$ and Ridouane (2008). The forms in (7) contain syllabic obstruents. 
(7) ts.ti 'she selected'

u.txk 'I struck you'

tf̣.tkt 'you suffered a sprain'

The selection of consonantal nuclei is phonologically predictable. Which of the segments in a sequence will be syllabic is governed by sonority: the syllabic consonant constitutes a local sonority peak. Dell \& Elmedlaoui (1985: 109) propose the sonority scale in (8).

(8) voiceless stops $<$ voiced stops $<$ voiceless fricatives $<$ voiced fricatives $<$ nasals $<$ liquids $<$ high vowels $<\mid$ a $\mid$

Thus a consonant can be syllabic if it is flanked by less sonorous segments (with a few exceptions, driven by the onset requirement). Crucially, when a nasal and a liquid are adjacent, it is the liquid rather than the nasal that becomes syllabic, regardless of the order in which the two segments occur, as shown in (9a). This justifies the ranking of nasals as less sonorous than liquids. A nasal becomes syllabic if flanked by less sonorous consonants, which, given its sonority status in the Imdlawn Tashlhiyt Berber-specific hierarchy in (8), have to be obstruents, as shown in the monosyllabic forms in (9b).

(9) a. iy.ml /I-yml/ 'it (MASC) went mouldy'

i.slm $/ I-\operatorname{slm} /$ 'it (FEM) went numb'

b. tzmt $/ \mathrm{t}-\mathrm{zmt} /$ 'it (FEM) is stifling'

tmzh /t-mzh/ 'she jested'

To conclude, in Imdlawn Tashlhiyt Berber, syllabic nasals are low-sonority nasals, i.e. they are less sonorous than liquids. There is no evidence for the status of nasals in onsets or codas, however, as both are simplex, and any consonant can occur at either margin.

3.1.2 Bulgarian (Indo-European, Slavic). In Bulgarian, a South Slavic language, crucial evidence for the relative sonority of liquids and nasals comes from syllable margins, in particular, from complex onset and coda clusters. The nucleus does not provide any evidence, as only vowels occur in this syllabic position. Our analysis is based on Scatton (1984).

The Bulgarian consonant inventory is given in (10). Generally, the palatalised series is highly restricted in its distribution: a palatalised consonant may not be followed by another consonant, and may not occur word-finally (/k g/ have predictable palatalised realisations $\left.\left[k^{j} \mathrm{~g}^{j}\right]\right)$. All consonants appear in simplex onsets, and all non-palatalised consonants, with the exception of voiced obstruents, appear in simplex codas.
plain
$\mathrm{ptkbdgfs \int xvz} 3 \mathrm{ctg} d 5 \mathrm{mn} 1$
palatalised $\mathrm{p}^{j} \mathrm{t}^{j} b^{j} d^{j} f^{j} v^{j} s^{j} z^{j} c^{j} m^{j} n^{j} 1^{j} r^{j}$ 
Bulgarian word-initial complex onsets feature a broad range of clusters, including those formed by two obstruents, as in (11a), an obstruent followed by a sonorant, as in (11b), and two sonorants, as in (11c). Only examples with non-palatalised consonants are given.
(11) a. obstruent + obstruent
pt bd st zd ps, etc.
b. obstruent + sonorant
pr pl pn km kr kl kn gm gr gl gn, etc.
c. sonorant + sonorant $\mathrm{mr} \mathrm{ml} \mathrm{mn} \mathrm{nr}$

While obstruent + sonorant clusters feature both nasals and liquids, leaving the issue of their relative sonority unresolved, sonorant + sonorant clusters clearly show that liquids are the more sonorous class. We find clusters with an initial nasal followed by a liquid, as in (12), but no clusters with an initial liquid followed by a nasal.
mlək 'quiet!'
mletfok 'milkweed'

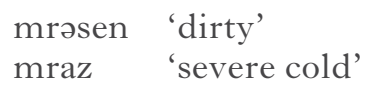

We can thus conclude that, in the onset, nasals are less sonorous than liquids, i.e. nasals have low sonority.

Complex codas also display three types of clusters, as in (13).
(13)
a. obstruent + obstruent $x t$ st $\int t$
b. sonorant + obstruent
$\mathrm{rp} \mathrm{rt} \mathrm{rtf} \mathrm{rk} \mathrm{lp} \mathrm{lt} \mathrm{lk}$
c. liquid + nasal
$\operatorname{lm} \ln$
d. liquid + liquid
rl

The first piece of evidence that low-sonority nasals occupy the coda is provided by the clusters in (13b), which include liquid-initial but not nasalinitial complex codas. The second piece of evidence comes from (13c), with clusters in which a liquid precedes a nasal, but no clusters with the reverse order. Clusters of the (13c) type are in fact rare, and we only found cases with $/ 1 /$ as the first member. Note also / rl/ in (13d), which suggests that $/ \mathrm{r} /$ is more sonorous than $/ 1 /$. Examples of $(13 \mathrm{~b}-\mathrm{d})$ are given in (14).

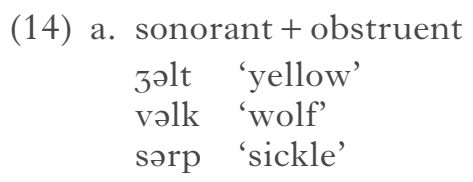

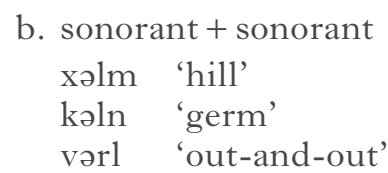

To conclude, in Bulgarian tautosyllabic clusters liquids pattern as more sonorous than nasals. This leads to the conclusion that the language has only low-sonority nasals.

3.1.3 English (Indo-European, Germanic). In English, both onset stop + C and coda clusters provide evidence for liquids being more sonorous than nasals. As shown in (15), all stops and fricatives (other than $/ \mathrm{s} /$ ) form onset 
clusters with a liquid as a second member, but not with a nasal (Clements \& Keyser 1983: 41-51). This pattern is consistent with the scenario in which liquids are more sonorous than nasals, as noted in Berent et al. (2007). ${ }^{5}$

\section{(15) $\mathrm{pl} \mathrm{pr} \mathrm{bl} \mathrm{br} \mathrm{fl} \mathrm{fr} \mathrm{tr} \mathrm{dr} \mathrm{kl} \mathrm{kr} \mathrm{gl} \mathrm{gr}$}

In coda clusters, both two obstruents and two sonorants can occur, as well as clusters featuring a sonorant followed by an obstruent. Both liquids and nasals can act as the first member of a coda cluster followed by an obstruent, as in milk, elf, bump and want. Crucially, clusters with two sonorants show that liquids are more sonorous than nasals, with the occurrence of $/ \mathrm{rm} /$ codas, as in harm, and $/ \mathrm{lm} /$ codas, as in helm, but no occurrence of $* / \mathrm{mr} /$ or $* / \mathrm{ml} /$ codas (Selkirk 1984: 119-126).

Both liquids and nasals can be syllabic. Nuclei thus do not shed light on their relative sonority. However, word-final liquids, as in kennel / kenl/or honour/onr/, are syllabic, while word-final nasals, as in kiln/kıln/ or horn /horn/, are not, further showing that liquids are more sonorous than nasals.

\subsection{High-sonority nasals only}

One of the diagnostics for high-sonority nasals is that only nasals are allowed in the coda, while any consonant in the inventory, including liquids, may occur in the onset. This pattern is exemplified by Gilbertese, Manam and Ikwere. Crucially, these languages have also liquids in their consonant inventories.

3.2.1 Gilbertese and Manam (Austronesian, Malayo-Polynesian). The discussion of Gilbertese is based on Blevins \& Harrison (1999) and Groves et al. (1985). Nasals may occur in both word-internal and wordfinal codas. Word-internally, $/ \mathrm{n} /$ and $/ \mathrm{n} /$ must share place features with a following consonant, as in /anti/ 'ghost', /bentira/ 'pencil', / $\mathrm{m}^{\mathrm{w}}$ ayko/ 'cup' and /euankerio/ 'gospel', while /m/ retains its place before any consonant (Groves et al. 1985: 14, 31, 35, Blevins \& Harrison 1999: 208). In word-final position, as shown in (16), coda nasals can be coronal, labial or dorsal (Groves et al. 1985: 7-8, 19). No other consonants appear in the coda.

(16) tim 'drop' $\quad$ man 'animal' $\quad$ kan 'to eat'
mim 'urine'

However, any consonant can occur in the onset, including liquids, as in /raoim/ 'your tranquility' and/arana/ 'his/her/its name'. Gilbertese also has syllabic nasals as the only syllabic consonants in the language, as in

${ }^{5}$ For completeness, we also mention the /s/-initial clusters /sp st sk/, which depart from the pattern in (15). The status of these sequences as only partially syllabified clusters (e.g. Levin 1985) or as complex segments (e.g. Selkirk 1982) has been extensively debated in the literature. 


\section{Martin Krämer and Draga Zec}

/mka/ 'compost', providing further evidence that nasals are more sonorous than liquids.

Another Austronesian language, Manam, also allows only nasals in the coda. According to Lichtenberk (1983: 28), nasals in medial codas agree in place with the following consonant, as in /lunta/ 'moss', /jambo/ 'guava' and /unguma/ 'person from a village other than one's own'. However, only $/ \mathrm{y} /$ and $/ \mathrm{m} /$ can occur in word-final codas, the two being in free variation, as illustrated in (17) (Lichtenberg 1983: 30-31).

$$
\begin{aligned}
& \text { a. day } \sim \text { dam 'water' } \\
& \text { boy } \sim \text { bom 'day, time' } \\
& \text { uzem } \sim \text { uzen 'I chewed them' } \\
& \text { b. udi gorani } \\
& \text { udi goray } \sim \text { udi goram 'eat the banana!' vs. }
\end{aligned}
$$

The coronal $/ \mathrm{n} /$ is realised as labial or dorsal word-finally, neutralising the place of articulation contrast, as illustrated by (17b). The nasal in 'banana' is underlyingly coronal, as shown by the singular form, and realised as dorsal or labial in the plural.

Manam has only simplex onsets. All consonants, including liquids, are permitted in the onset, as exemplified by /roa/ 'spouse', /lunta/ 'moss' and /alea/ 'month'. Note, however, that Manam has no syllabic consonants. Having only vowels as syllable nuclei is consistent with the language only having high-sonority nasals.

\subsubsection{Ikwere (Niger-Congo, Igboid). Neither Gilbertese nor Manam pro-} vides direct evidence for the high-sonority status of onset nasals. But the patterning of nasality in Ikwere strongly suggests that high-sonority nasals occur in all three syllabic positions, coda, nucleus and onset. According to Clements \& Osu (2005), nasals are the only consonants that occur in surface forms as codas and as nuclei. Examples of codas are given in (18a) and (b), and of nuclei in (c). Note that only $/ \mathrm{m} /$ can occur as a word-final coda consonant. The consonantal nuclei in $(18 \mathrm{c})$, referred to by Clements \& Osu (2005: 172-173) as 'moraic nasals', occur only word-initially and preconsonantally, and belong to the morphological root. They are realised as $/ \mathrm{m} /$ before bilabials and as $/ \mathrm{n} /$ elsewhere. Thus Ikwere codas and nuclei exhibit the high-sonority nasal pattern.

a. final codas
òdùm 'lion'
sákáḿ 'ray'
b. medial codas
álángá 'needle'
sấmbì 'key'
ńgàngà 'conceitedness'
tònjì 'lamp'

c. syllabic nasals

$\begin{array}{ll}\text { ṇ̀pú } & \text { 'jigger' } \\ \text { ṇfù } & \text { 'horn' } \\ \text { ńrî̀ } & \text { 'ten' } \\ \text { ǹ̀gàdấ } & \text { 'chair' } \\ \text { ṇ́hwù } & \text { 'loss' } \\ \text { ṇ́wố } & \text { 'child' }\end{array}$


The distribution of nasality in onsets strongly suggests that high-sonority nasals occupy this syllabic position as well. There are two series of Ikwere vowels, oral and nasal, and the two are contrastive, as shown in (19). ${ }^{6}$

$$
\begin{aligned}
& \text { ézí 'big' } \quad \text { vs. ézĩ̀ 'pig' } \\
& \text { ódó 'mortar' vs. òdồ 'yellow dye' }
\end{aligned}
$$

The distribution of the feature [+nasal] is predictable in onsets. The obstruents in (20a) freely co-occur with both oral and nasal vowels. However, the oral non-obstruents $/ \mathrm{b}^{\mathrm{P}} \mathrm{b} /$ and sonorants in (b) are in complementary distribution with the nasals in (c): the former may only precede an oral vowel, while the latter may only precede a nasal vowel. ${ }^{7}$

(20) a. obstruents

$$
\text { stops }
$$

fricatives

b. oral non-obstruents

voiced non-explosive stops

glottalised non-explosive stops

lateral approximants

central approximants

aspirates

c. nasal non-obstruents

plain stops

glottalised nasal stops

central approximants

aspirates p tc k k ${ }^{w} b d_{J} g g^{w}$

f s v Z

b

${ }^{\mathrm{P}} \mathrm{b}$

1

r j y w

$\mathrm{h} \mathrm{h}^{\mathrm{w}}$

$\mathrm{m} \mathrm{n}$

${ }^{\mathrm{P}} \mathrm{m}$

$\tilde{\mathrm{r}} \tilde{\mathrm{j}} \tilde{\mathrm{Y}} \tilde{\mathrm{w}}$

$\tilde{\mathrm{h}} \tilde{\mathrm{h}}^{\mathrm{w}}$

Examples are given in (21).

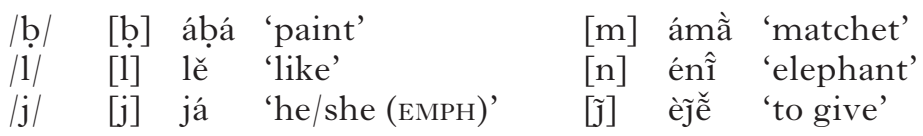

In sum, nasality spreads from a nasal vowel to preceding sonorant and non-obstruent consonants, but not to preceding obstruents. This strongly suggests that the onset nasals that emerge through this process have high

${ }^{6}$ Clements \& Osu (2005) further argue that nasality is contrastive at the morpheme level rather than at the level of segment, with some morphemes associated with a floating [+nasal] feature. While this is a plausible perspective, for our purposes it is sufficient to assume that vowels contrast in nasality.

7 Clements \& Osu (2002) provide a detailed, experimentally informed analysis of the status of $/ \mathrm{b} /$ and $/{ }^{\mathrm{P}} \mathrm{b} /$. These sounds are classified as non-obstruent stops, characterised by a complete closure but lacking pressure build-up prior to release. As such, they share some obstruent traits, and pattern only partially with sonorants. Clements \& Osu propose that they are [-obstruent, - sonorant]. However, with regard to the distribution of nasality, these sounds do pattern with sonorants, and this is of central relevance for establishing the status of nasal consonants in Ikwere. 
sonority, and thus have the same sonority status as nasals in codas and nuclei.

A comment is in order on Clements \& Osu's (2005) central claim that nasality in Ikwere is contrastive in vowels, but not in consonants. In particular, they derive all surface nasals from nasal vowels. However, we note that, although nasals are predictable in onsets, this is not the case in either nuclei or codas.

Clements \& Osu analyse syllabic nasals such as those in (18c) as corresponding underlyingly to a nasalised schwa / $/$ /, motivated by the fact that they are in free variation with this vowel. However, / $\tilde{\partial} /$ is not included in the vowel inventory, nor can other nasal vowels occur in word-initial position, the only position occupied by the syllabic nasal. While the vocalic analysis of the moraic nasal is motivated by a desire to maintain the generalisation that all nasal consonants are derived from nasal vowels, its abstractness incurs more cost than is necessary. In our analysis, the syllabic nasal is a high-sonority nasal, which accounts for its free variation with the nasalised vowel. This also explains its co-occurrence with any following consonant, including sonorants and glides, as shown in 'ten' and 'child' in (18c). This patterning is consistent with an interpretation as a high-sonority nasal, which lacks a continuancy specification.

Clements \& Osu propose an even more abstract analysis of coda nasals. Word-final nasals, as in (18a), are analysed as corresponding to an underlying / bạ̃/ sequence, predictably yielding the nasal allophone of / $b$ / before a nasal vowel, which in turn subsequently deletes; for example, the underlying form of [òdùme] is /òdùbấ/ (Clements \& Osu 2005: 194). While this ingenious analysis captures the nasal's bilabial place and its ability to bear tone, it suffers from excessive abstractness. In order to justify the /bã/ source of the final nasal, Clements \& Osu invoke several phonotactic generalisations, one being that, if $/ \mathrm{m} /$ were posited in place of $/ \mathrm{b} \tilde{z} /$, the nasal would be the only coda consonant. This, however, is neither unusual nor rare. As we have already seen, if only one consonant is allowed in the coda, it will most likely be a nasal, in particular a high-sonority nasal. Another phonotactic generalisation that the / bã / analysis is intended to capture is the ability of the coda nasal to bear tone. But if the coda nasal is a high-sonority nasal, its tone-bearing capacity should be similar to that of vowels. ${ }^{8}$

Unlike word-final coda nasals, word-medial coda nasals, as in (18b), are not analysed by Clements \& Osu as underlying / bã / sequences. Instead, their analysis (2005: 173) parallels that of syllabic nasals, with the vowel $\mid \tilde{a} /$ as their underlying counterpart. Another apparent parallel with syllabic nasals is that nasals in medial codas assimilate in place to the following

8 Another generalisation offered by Clements \& Osu (2005: 194-195) in support of the /ḅ̃ / source concerns tonal melodies that stretch over two syllables, and are also found on $/ \mathrm{CVm} /$ sequences. This generalisation could be interpreted in terms of moras in place of syllables. If the word-final nasal is moraic, and if the mora is a tone-bearing unit, tonal melodies stretch over two moras (which in some cases also correspond to two syllables). 
consonant, which is actually a property of any preconsonantal nasal, regardless of its prosodic position. We generalise that both coda positions allow nasals, in particular high-sonority nasals, with the labial place realised word-finally. ${ }^{9}$

We conclude that, just like syllabic nasals, both word-medial and wordfinal coda nasals correspond to high-sonority nasals which are unspecified for continuancy. Clements \& Osu's insightful but overly abstract analysis may well be valid as a diachronic account of nasal phonotactics in Ikwere.

\subsection{Sonority by position}

Sonority by position is consistent with several scenarios. Both low- and high-sonority nasals are active in the phonological systems of type 3 languages in Table III, but they occupy distinct, non-overlapping syllabic positions. This situation is found in Wan and Sentani.

3.3.1 Wan (Niger-Congo, Mande). The presentation here is based on Ravenhill (1982), which focuses on the Kemmu dialect.

Nasals occur in all positions in Wan, i.e. in onsets, codas and nuclei. Moreover, they are the only consonants that can occur in the coda and the nucleus, as shown in (22a) and (b) respectively; in these positions they act as tone-bearing segments. Syllabic nasals occupy word-initial position and assimilate in place to the following consonant, while coda nasals are invariably dorsal.

a. only nasals occur in coda
lóǹ 'eye'
mlĩy do 'twenty'
bo.ley 'moon'
bóń.glõ 'head'10
b. only nasals are syllabic ǹ.dé 'my father' mì.bèǹ 'my compatriot' ỳ.gbè 'my son'

The inventory of Wan consonants is given in (23). ${ }^{11}$

9 Clements \& Osu $(2005: 173)$ note that /â/ 'loses its tone-bearing capacity wordinternally where it always shares the phonetic tone of the preceding vowel', further suggesting that, in this position, the coda nasal 'appears to have the status of a consonant'. We adopt this tentative suggestion, assuming a special allophonic status for medial nasal codas adjacent to stop consonants.

10 Ravenhill assumes that coda nasals are dorsal, as in (22a). Either the example 'my compatriot' in (22b) is a typo or it shows that Ravenhill's generalisation is too restrictive.

11 Ravenhill analyses the bilabial nasal as an allophone of the bilabial implosive /6/. Like other nasals, $/ \mathrm{m} /$ is invariably followed by a nasalised vowel in onset position. The bilabial implosive, however, is the only implosive in the language, and is also the only obstruent that may not be followed by a nasalised vowel. We therefore assume that, due to its highly restricted distribution, the bilabial implosive is the allophone of the bilabial nasal in positions before an oral vowel. This analysis yields a more balanced inventory, with nasals at all three places of articulation, and with no contrastive status for the sole implosive. 


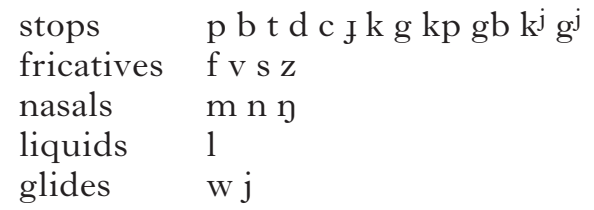

The sonorants include the nasals $/ \mathrm{m} \mathrm{n} \mathrm{y} /$ (with $/ \mathrm{m} /$ realised as implosive [6] before an oral vowel), and a single liquid, realised as [r] after alveolars and as [1] elsewhere. In light of this, the pattern in (22) corresponds to the high-sonority nasal scenario, with nasals more sonorous than liquids.

In onsets, however, we observe low-sonority nasals. Any consonant in the inventory, whether obstruent or sonorant, can appear as a singleton onset. Wan also has complex onsets, and here the patterning of sonorants is consistent with a low-sonority nasal categorisation. Complex onsets with an obstruent as the first member allow only a liquid as the second member. Since the set of complex onsets includes OL but not ON, as shown in (24), we conclude that, in onsets, liquids are more sonorous than nasals.

$\begin{array}{lll}\text { (24) } & \text { 6lè 'snake' } & \text { 6ón.glõ 'head' } \\ \text { kla 'behind' } & \text { ká.blu 'belly' } \\ \text { tre 'night' } & \text { blè.kó 'run' } \\ \text { troj́ 'ground' } & & \end{array}$

There is also one case listed with a complex onset consisting of a bilabial nasal followed by a liquid, /mling do/ 'twenty'. This cluster is again consistent with the low-sonority nasal patterning (see note 11 on the status of the bilabial nasal).

In sum, we find the two types of nasals in complementary distribution: low-sonority nasals in onsets, and high-sonority nasal in codas and nuclei.

3.3.2 Sentani (Sentani, Sentani). Another case of complementary distribution between high- and low-sonority nasals is found in Sentani, spoken in West New Guinea. Our presentation is based on Cowan (1965) and Foley (1986). Sentani has only ten consonants in its inventory: three stops $/ \mathrm{p} \mathrm{t} \mathrm{k} /$, two fricatives $/ \mathrm{f} \mathrm{h} /$, two nasals $/ \mathrm{m} \mathrm{n} /$, a liquid $/ 1 /$ and two glides $/ \mathrm{w} \mathrm{j} / .^{12}$ Syllables are maximally CVC, with only vowels as syllable nuclei, and only nasals and glides in the coda, as illustrated in (25).
a. 'joku 'dog'
ho'kolo
'young'
u'kəwnə 'he told him'
mə'kajde 'they came'
'kambi 'neck'
b. fa'ləm 'head'
hodo'bom 'let me kill'
ə'ləj 'speak!'
an'kej 'ear'
a'waw 'mother's brother'

12 Cowan (1965: 6) gives the set of stops as / $\mathrm{b} \mathrm{d} \mathrm{k} /$, noting that 'the plosives $/ \mathrm{b} /$ and $/ \mathrm{d} /$ are unvoiced lenes, respectively bilabial and gingival, but free non-distinctive variants include unvoiced and voiced types'. Here we follow Foley (1986: 59), where the set of Sentani stops is given as $/ \mathrm{p} \mathrm{t} \mathrm{k/.}$ 
Coda nasals are weight-bearing, as indicated by the distribution of stress, which falls on the final closed syllable, as in (25b), and otherwise on the penultimate, as in (a). Given that only nasals occur in the coda, even though liquids are present in the inventory, we have a high-sonority nasal pattern.

The situation in onsets, however, suggests a low-sonority nasal scenario. Sentani has only simplex onsets. Of interest here is the fact that the liquid is excluded from word-initial onsets as well as some word-medial onsets. As stated by Cowan (1965: 7), the phoneme /1/ 'only occurs intervocally and never as word-initial nor after consonant. In the latter two positions it is represented by $/ \mathrm{d} /$ as bound and obligatory heterophonemic variant'. However, nasals are not restricted in this fashion, as shown by examples such as [mannam] $(\leftarrow / \mathrm{m}$-am-n-am/) 'come (and) stick', strongly suggesting that, in onsets, they are less sonorous than liquids. ${ }^{13}$ Viewed from the perspective of syllable contact (Vennemann 1972, Zec 2007 and references therein), these facts further suggest that the sonority distance between a coda nasal and an onset nasal (that is, between a high-sonority and a low-sonority nasal) is greater than that between a coda nasal and a following liquid.

To summarise, codas privilege high-sonority nasals, while onsets privilege low-sonority nasals. In both cases, nasals are selected over liquids: in codas as higher-sonority nasals, and in onsets as lower-sonority nasals. This analysis is further supported by syllable-contact patterns.

\subsection{High- and low-sonority nasals in contrast}

The theory proposed here allows for a contrast between high- and lowsonority nasals in the same position. In terms of features, one [nasal] segment is specified as [-continuant] and the other is not. There is a range of options with respect to how this difference is reflected in the phonetic realisation of the two segments. Indicative of this is the phonetic variation we find in languages with small inventories, for example those of Central Rotokas or Maxakalí, discussed briefly in \$2.2. In the latter language, nasals can be variably realised as plain nasals, prenasalised stops or glides. One can reasonably argue that this wide phonetic variation is possible in these languages because these consonants are specified neither for [-continuant] nor for [nasal], but rather only for place of articulation. The same phonetic distinction, i.e. between $\left[{ }^{\mathrm{m}} \mathrm{b}\right]$ and $[\mathrm{m}]$, is used contrastively in some languages. To illustrate this we first, in $\$ 3.4 .1$, consider Fijian, Pamona, Mbay and Wambon, where we establish the highsonority/low-sonority contrast in the onset. The following two subsections are devoted to cases illustrating contrasting nasals in non-onset position, Ciyao (\$3.4.2) and Polish (\$3.4.3).

13 Glides occur word-initially, predominantly as allophones of high vowels. According to Cowan (1965: 7-8), they are only marginally phonemic, with a low functional yield. It may well be that these word-initial glides are in fact nuclear offglides, following Smith's (2007) proposal for the Iglesias dialect of Campidanian Sardinian, which presents a situation parallel with that in Sentani. 
3.4.1 Fijian, Pamona, Mbay and Wambon. Fijian(Austronesian) is generally analysed as a CV language with simple onsets, whose consonant inventory includes voiceless stops and voiced prenasalised stops and nasals, as well as a small set of fricatives, two liquids and a prenasalised trill (Schütz 1985). That is, Fijian does not have a voiced stop series; rather, its place in the system is occupied by voiced prenasalised stops. This is reflected in loanword adaptation: voiced stops in English forms such as doctor and belt become prenasalised, yielding /ndoketa:/ and /mbeleti/ respectively (Hayes 1995). Of central interest here is the contrast between plain nasals and prenasalised stops, in both word-initial and word-medial onsets, which we interpret as a contrast between high- and low-sonority nasals. If they were analysed as clusters, prenasalised stops would be the only onset clusters in a language in which no other consonant sequences are permitted.

Pamona (Austronesian) has more consonants than Fijian, and presents a clearer case of the plain nasal $v s$. prenasalised stop contrast. The description is based on Riehl (2008), who analyses Pamona as a CV language, with no consonants in the coda. The Pamona consonant inventory includes both voiceless $(/ \mathrm{p} \mathrm{t} \mathrm{k} /)$ and voiced $(/ \mathrm{b} \mathrm{d} \mathrm{g/)}$ stops, a voiced affricate $(/ \mathrm{d} / /)$, plain nasals $(/ \mathrm{m} \mathrm{n} \mathrm{y} /)$, a single fricative $(/ \mathrm{s} /)$, two liquids $(/ \mathrm{r} 1 /)$, a glottal stop and a series of both voiced and voiceless prenasalised stops and affri-

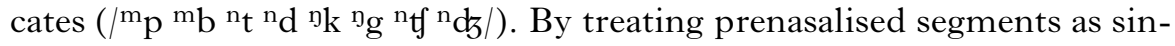
gletons, we depart from Riehl's (2008) analysis, where they are NC sequences. Riehl's analysis raises two problems. First, NC sequences would be the only consonant clusters in Pamona, and thus the only type of complex onset. Second, $/{ }^{n} \mathfrak{t} /$ cannot be analysed as a sequence, because there is no $/ \mathrm{t} /$ in the consonant inventory. Riehl addresses this by deriving the nasal $+\mid \mathfrak{t} /$ sequence from nasal $+/ \mathrm{s} /$, with $/ \mathrm{s} \mid$ then strengthened to $/ \mathfrak{t} /$. However, analysing $/ \mathrm{n}^{\mathfrak{g}} /$ as an underlying nasal $+\mid \mathrm{s} /$ sequence leads to absolute neutralisation, since $/{ }^{n} \mathfrak{f} /$ occurs in monomorphemic forms such as $/ \mathrm{a}^{\mathrm{n}} \mathrm{t} \mathrm{ja} /$ 'mango' and $/ \mathrm{to}^{\mathrm{n}} \mathrm{t} \mathrm{j} /$ ' 'bird'.

In light of this, we interpret prenasalised stops and affricates as single segments, and analyse Pamona as a CV language with simplex onsets. The contrasts at the coronal place, in both word-initial and medial position, are illustrated in (26); examples are from Riehl (2008).

$\begin{array}{ll}\text { a. word-initial } & \\ \text { neka (name) } & \text { nana 'wound' } \\ \text { deki (name) } & \text { tana 'earth' } \\ \text { ndeki 'to climb' } & \text { ntani 'another' } \\ \text { b. word-medial } & \\ \text { tono 'to knock head' } & \\ \text { todo 'at ease', } & \text { toto 'pair, counterpart' } \\ \text { to }{ }^{\text {ndo }} \text { 'next to' } & \text { to }{ }^{n} \text { to 'to empty out' }\end{array}$

To conclude, Fijian and Pamona exemplify a contrast between high- and low-sonority nasals in the onset, with plain nasals behaving as highsonority nasals, and prenasalised stops as low-sonority nasals. 
Mbay (Nilo-Saharan) and Wambon (Trans-New Guinea) contrast nasals and prenasalised (voiced) stops in the onset (de Vries \& de Vries-Wiersma 1992, Keegan 1997), interpreted here as a contrast between high- and low-sonority nasals. While Mbay also distinguishes between voiced and voiceless stops, Wambon has only the voiceless series. Both languages also have codas. Both liquids and plain nasals occur in codas in Mbay, so that we analyse the nasals as having high sonority. Wambon allows both stops and nasals in coda position. Based on this inventory we conclude that Wambon has low-sonority nasals in the coda, specified as [-continuant], just like the stops. In the absence of a contrast between high- and low-sonority nasals, these can be realised as plain nasals, which we assume to be the default phonetic realisation for nasals.

3.4.2 Ciyao (Niger-Congo, Bantu). Another case of contrasting high- and low-sonority nasals is provided by Ciyao. According to Hyman \& Ngunga (1997), Ciyao has two contrasting nasals, referred to as 'moraic' and 'syllabic'. Both occupy preconsonantal position, and both are weightbearing, but they differ in how they interact phonologically with surrounding segments. ${ }^{14} \mathrm{We}$ argue that the two nasals occupy different positions on the sonority hierarchy: the 'moraic' nasal is low-sonority, and the 'syllabic' nasal is high-sonority.

We start with the 'moraic' nasal, which 'has an effect both on the preceding vowel as well as on the following consonant' (Hyman \& Ngunga 1997: 133). This segment occurs in both roots and prefixes, one of which is the 1 st person singular object prefix /-N-/ illustrated in (27); the leftmost column shows the lexical forms of morphemes. We focus here on its interactions with obstruents, which, according to Ngunga (2000: 53), are $/ \mathrm{p} \mathrm{b} \mathrm{t} \mathrm{d} \mathrm{k} \mathrm{g} \mathrm{t} \mathrm{d} \mathrm{s} /$. If the following obstruent is [-continuant] the nasal merges with it, acquiring its place of articulation. A following voiceless obstruent becomes voiced (27a), and a voiced obstruent is deleted (b). Departing from this pattern is $/ \mathrm{d} /$, which doesn't delete $(27 \mathrm{c})$. But if the following obstruent is $/ \mathrm{s} /$, that is, if it is [+continuant], the nasal is deleted $(\mathrm{d}) .{ }^{15}$

14 Hyman \& Ngunga (1997: 158) also posit a third type of preconsonantal nasal, which they represent as 'an underlying prenasalised consonant'. This case is outside the scope of this paper.

15 The 'moraic' nasal also interacts with root-initial sonorants (approximants, liquids and nasals), the pattern paralleling that with voiced obstruents: these segments delete in postnasal position, occasioning compensatory lengthening in the preceding vowel. 
(27) a. postnasal voiceless obstruent voices

ku-N-péleka $\rightarrow$ kuumbéleka 'to send me'

ku-N-túma $\rightarrow$ kuundúma 'to order me'

ku-N-kwéela $\rightarrow$ kuungwéela 'to climb on me'

b. postnasal voiced obstruent (other than $/ \mathrm{d} /$ ) deletes

ku-N-búútfila $\rightarrow$ kuumúútfila 'to be angry with me'

ku-N-góneka $\rightarrow$ kuunóneka 'to make me sleep'

c. postnasal voiced $/ \mathrm{d} /$ is unaffected

ku-N-dípa $\rightarrow$ kuundípa 'to pay me'

$\mathrm{ku}-\mathrm{N}$-délela $\rightarrow$ kuundélela 'to underestimate me'

d. nasal deletes before $/ \mathrm{s} /$

ku-N-sóosa $\rightarrow$ kuusóosa 'to look for me'

In all cases, the vowel of the infinitive prefix / $\mathrm{ku}-/$ is lengthened: the nasal moves to the following onset, leaving behind a mora, which then causes compensatory lengthening of the preceding vowel (Hyman \& Ngunga 1997: 137). ${ }^{16}$

The 'syllabic' nasal, illustrated here with the $2 \mathrm{nd} / 3 \mathrm{rd}$ person singular object prefix, differs from the 'moraic' nasal on at least two counts: it doesn't interact with the voicing of the following obstruent and it doesn't trigger lengthening in the preceding vowel. As shown in (28), the 'syllabic' nasal assimilates in place with any following consonant, regardless of its continuancy, and doesn't delete in any of the contexts. (Following Hyman \& Ngunga, the 'syllabic' nasal is marked with a diacritic, /'/.)

(28) a. postnasal voiceless obstruent remains voiceless

ku-N-péleka $\rightarrow$ kum'péleka 'to send you/him'

ku-N-túma $\rightarrow$ kun'túma 'to order you/him'

ku-N-kwéela $\rightarrow$ kuy'kwéela 'to climb on you/him'

b. postnasal voiced obstruent (other than $/ \mathrm{d} /$ ) remains voiced ku-N-búúcila $\rightarrow$ kum'búúcila 'to be angry with you/him' ku-N-góneka $\rightarrow$ kuy'góneka 'to make you/him sleep' ku-N-vácíla $\rightarrow$ kum’bácila 'to build for you/him'

c. postnasal voiced $/ \mathrm{d} /$ remains voiced ku-N-dípa $\rightarrow$ kun'dípa 'to pay you/him' ku-N-déléla $\rightarrow$ kun'déléla 'to underestimate you/him'

d. nasal does not delete before / $/$ ku-N-sóósá $\rightarrow$ kun'sóósá 'to look for you/him'

16 The 'moraic' nasal is realised as a nasal consonant before a vowel-initial form, as in /diisó n-áá-túmilé/ 'yesterday I ordered', where it acts as a subject prefix (Hyman \& Ngunga 1997: 138-139). The authors claim that the tense marker /-á-/ is subject to compensatory lengthening because the 'moraic' nasal lands in the onset. However, they also allow for the possibility that the tense marker is underlyingly long (1997: 139, n. 7). Here we adopt the latter interpretation. 
Moreover, the 'syllabic' nasal parallels the phonological behaviour of vowels in its ability to bear tone, as shown in /eeló ń'tumile/ 'today you ordered', where it acts as a 2 nd person singular subject prefix (Hyman \& Ngunga 1997: 142).

Crucially, the two types of nasals contrast, as both occur before consonants and, according to Hyman \& Ngunga, both are in the coda. Evidence that the 'syllabic' nasal occupies the coda (despite its name) comes from two phonological processes. First, a long vowel shortens when preceding a 'syllabic' nasal prefix, as in (29). This process is naturally accounted for as closed syllable shortening, with the nasal syllabified in the coda.

\section{(29) vaḿpeleéce 'they sent you/him' (cf. vaapéleéce 'they sent')}

Second, while the 'syllabic' nasal is vowel-like in its tone-bearing capacity, it parallels the behaviour of vowels associated to the second mora of the syllable, but not of those associated with the first mora (Hyman \& Ngunga 1997: 145-147). ${ }^{17}$ This, again, argues for syllabifying the 'syllabic' nasal in the coda, and linking it to the second mora within the syllable. In sum, while both nasals start out in preconsonantal position, only the 'syllabic' nasal occupies this position at the surface. Association with the coda is obscured in the case of the 'moraic' nasal, due to the phonological processes detailed above.

Hyman \& Ngunga capture this contrast by placing the burden of explanation on the higher levels of prosodic representation: both morphemes consist underlyingly of a nasal and a mora, but only the 'syllabic' nasal is also prelinked to a mora. In contrast, we propose that the difference between the two nasals should be captured at the segmental level. The 'moraic' nasal is a low-sonority nasal specified as [+nasal, -continuant], while the 'syllabic' nasal is a high-sonority nasal specified merely as [+nasal], as in the representations in (30).

$$
\begin{array}{ll}
\text { moraic } & {[+ \text { nas, }- \text { cont }]} \\
\text { syllabic } & {[+ \text { nas }]}
\end{array}
$$

Crucially, the continuancy specification determines the phonological processes that the two nasals participate in. Following Padgett (1991), we assume that the low-sonority nasal, marked as [-continuant], can share a place specification only with a following [-continuant] segment (and is deleted from the structure in the absence of such a segment). The high-sonority nasal, which lacks a specification for continuancy, freely adopts the place of any following segment. In sum, while the lowsonority nasal exhibits an affinity to obstruents, the high-sonority nasal is close in its phonological behaviour to vowels, in particular those that are dominated by the second mora within the syllable. Due to their

17 When associated with the head mora, the syllabic nasal exhibits allomorphy, and is realised as /mu-/ (Hyman \& Ngunga 1997: 150-154). 


\section{Martin Krämer and Draga Zec}

different featural make-up, the two nasals occupy different positions on the sonority hierarchy. The contrast between the two nasals within the coda is due to the differences in their underlying feature specifications.

3.4.3 Polish (Indo-European, Slavic). Polish also has two types of nasal, both of which are found in rhymes. The nasal vowels are phonetically different from those in other languages with an oral-nasal contrast in vowels, as Gussmann (2007: 2) observes:

Here we would like to note that nasal vowels as found in, say, French are not attested in Polish; what we do find are mid vowels $[\varepsilon, 0]$ followed by a

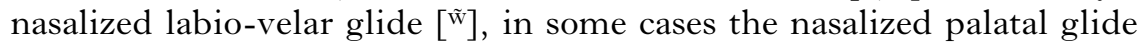
[j], hence the nasal nuclei are better regarded as diphthongs.

This is consistent with Paradis \& Prunet's (2000) claim that the default representation of nasal vowels is bisegmental. According to Bethin's (1988) overview, Polish nasal vowels are realised as the diphthongs [ $\varepsilon \tilde{w}$

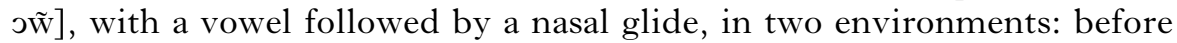

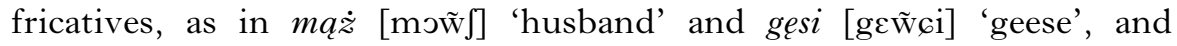

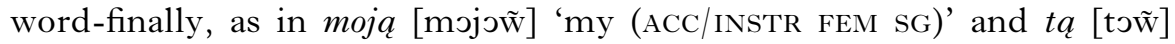
'that'. In our analysis, these nasal glides are high-sonority nasals. Nasal glides differ from plain nasals, which are specified as [-continuant], and occur in both prevocalic and postvocalic positions - they are analysed here as low-sonority nasals. The two types of nasals contrast before fricatives, as shown by gesi [geñci] vs. chamski [xamsci] 'boorish'. They also contrast in word-final position ( $t a$ [tow $]$ vs. ton [ton] 'tone'; Bethin 1988: 45).

Bethin (1988) also observes that, when a nasal vowel is followed by a stop, its glide portion is realised as a homorganic nasal consonant, as in $d a b$ [domp] 'oak tree' and rece [rence] 'hands'. Since low-sonority nasals retain their place features before stops, as in hańba [xanba] 'shame' and stomka [swomka] 'straw (DIM)', the contrast between high- and low-sonority nasals is only partially neutralised in this environment.

A dissenting opinion comes from Zaleska \& Nevins (2015), who claim that nasal vowels in Polish are not bisegmental structures. They carried out an experiment in which participants were asked to delete coda consonants as part of a word game. In word-internal position, the only environment that figured in the experiment, the nasal glide portion of the biconsonantal structure was rarely deleted, leading Zaleska \& Nevins to the conclusion that nasal vowels correspond to one segment, rather than two, and that their nasality is realised as a feature on the vowel, rather than as a nasal glide. However, the results of this experiment are less than conclusive, in light of the fact that the stimuli included only forms with nasal vowels in word-medial preconsonantal position, providing no comparison with proper nasals, or with non-nasal consonants.

Beyond the phonetic surface distinction between nasal glides and proper nasals, Polish does not provide further evidence for the criteria established 
in this paper. Onset phonotactics are extremely liberal in Polish, with sonority reversals in complex onsets being allowed. Since Polish also has onset sequences that observe sonority sequencing, the emergence of sonority reversals should be attributed to the low ranking, or absence, of phonotactic restrictions on complex onsets (see Bethin 1992: 38-41).

\subsection{Discussion}

In this section we have provided evidence for the dual nasal typology in Table III, presenting examples of each of the four predicted language types. Three out of the four types exhibit hitherto unidentified clusterings of phonological properties, i.e. all except type 1 in Table III, which has only low-sonority nasals. In sum, this typology crucially rests on positing high-sonority nasals alongside low-sonority nasals, and on a general preference for low-sonority nasals in onsets and high-sonority nasals in the rhyme.

The typology in Table III is based on the set of criteria presented in Table II. Of interest here is how well these criteria distinguish between low- and high-sonority nasals. We have found in our database languages with only nasals but no liquids in the coda, as stated in (a.i) in Table II, or in the nucleus, as in (a.ii), which according to these criteria have high-sonority nasals. Turning to criteria (b.i) and (b.ii), which serve as a basis for classifying languages as having low-sonority nasals, we found cases where liquids are privileged over nasals as syllabic consonants, as predicted by (b.ii), but no corresponding strong evidence that coda liquids are privileged over nasals, as predicted by (b.i). Moreover, we identified languages with complex onsets that conform to criteria (b.iii), privileging NL over LN, and (b.iv), privileging OL over ON, which classifies them as possessing low-sonority nasals. However, there are no languages with complex onsets that exhibit the patterning in (a.iii), privileging $\mathrm{LN}$ over $\mathrm{NL}$, and (a.iv), privileging ON over OL, consistent with high-sonority nasals. We also found languages which privilege $\mathrm{N}$ in onsets over $\mathrm{L}$, as expected if nasals are less sonorous than liquids (b.v), but no languages that privilege $\mathrm{N}$ over $\mathrm{L}$ in onsets (a.v). We conclude that, at least in our database, high-sonority nasals are better documented in nuclei and codas, while low-sonority nasals are better documented in the onset. This is suggestive of an onset-coda asymmetry. Thus type 3 in Table III includes languages with low-sonority nasals in the onset and high-sonority nasals in the coda; but none with the reverse pattern, i.e. with high-sonority nasals in the onset and low-sonority nasals in the coda. However, in type 4, we found a contrast between low- and highsonority nasals in both the onset and the coda. This asymmetry may well be part of a more general patterning, with low-sonority segments more likely to occur in the onset, and high-sonority segments more likely to occur in the coda, or rather, in the rhyme.

A further important question is whether a sonority split in nasals can be reinterpreted as a sonority split in liquids. This alternative scenario would 


\section{6}

not affect the accounts of languages with only one type of nasal. Languages analysed here as having only low-sonority nasals could be reinterpreted as having high-sonority liquids, while languages with only high-sonority nasals could be reinterpreted as having low-sonority liquids. Under either scenario, the relative sonority of nasal and liquids will remain the same. This alternative analysis is of course irrelevant for cases of lowand high-sonority nasals in contrast. However, such a reinterpretation would definitely have consequences for the analysis of languages with high- and low-sonority nasals in complementary distribution. For example, can we reinterpret the situation in a language like Wan as having high- and low-sonority laterals (as its only liquid is $/ 1 /$ ), rather than high- and low-sonority nasals? If we take this route, then high-sonority liquids will be associated with the onset, and low-sonority liquids with the coda. That is, we would have to claim that high-sonority $/ 1 /$ is preferred over less sonorous nasals in the onset, while low-sonority / $1 /$ yields to the more sonorous nasals in the coda. However, this goes against the general tendency for lower sonority in onsets than in codas. This generalisation is observed in the analysis we propose: with a sonority split in nasals, the low-sonority subclass occupies the onset, and the high-sonority subclass is in the coda.

If nasals exhibit dual patterning, as we have argued, we might ask whether this is also the case with other segment classes, and an obvious class to consider are laterals. As claimed in Mielke (2005), both nasals and laterals can pattern as either [-continuant] or [+continuant] (see also Yip 2011). In $\$ 2.3$ we argued that the distinction between high- and low-sonority nasals cannot be represented in terms of opposite values for the feature [continuant], and we extend this perspective to the class of laterals. That is, in light of our criteria, both types of laterals posited by Mielke constitute a single sonority class.

This leaves the question of whether there is some other phonological basis for the dual sonority patterning of laterals, or liquids in general, of the sort established here for nasals. Any more informed discussion of this issue would need to be based on a set of clear criteria that parallel those we have established for nasals. While at this point we can only speculate, we mention here some potentially relevant cases. One concerns the co-presence in consonant inventories of lateral fricatives and lateral approximants, which may well represent the low- and high-sonority members of this segment class. Another candidate for a low-sonority lateral (brought to our attention by the associate editor) is found in Southern Min, where, according to Yip (2011: 736), '[1] is the modern reflex of historical $* \mathrm{~d}$ ', patterning synchronically with voiced obstruents. Thus 'underlyingly $/ \mathrm{p} \mathrm{t} \mathrm{k/} \mathrm{voice} \mathrm{into} \mathrm{[b} \mathrm{l} \mathrm{g]} \mathrm{foot-internally'.} \mathrm{Moreover,} \mathrm{a}$ relatively plausible candidate for a high-sonority lateral could be found in Slovak, in which $/ 1 /$ and $/ \mathrm{r} /$ are the only syllabic consonants (Kenstowicz \& Rubach 1987, Zec 2013). The two liquids pattern closely with vowels, exhibiting contrastive length (in a language that lacks geminates), and participating in alternations of nuclear length (in a process 
known as the 'rhythmic law'). Thus, unlike nasals, which may not constitute syllable peaks, or for that matter, exhibit contrastive length, syllabic /1/ is close to the vocalic realm. Whether facts of this nature are suggestive of a sonority split within the class of laterals, or liquids in general, is an issue for future research.

\section{Nasals and place of articulation}

The predominance of nasals as the only manner class permitted in the coda has been associated with their ability to be placeless. In the influential proposal of Itô $(1986,1989)$ and Itô \& Mester (1993), restrictions on coda inventories are attributed to a prohibition on the occurrence of contrastive consonantal place features in the coda. This prohibition, formally expressed in Itô (1989) as a coda filter, is circumvented by placeless consonants such as nasals (as well as laryngeals or geminates). The coda pattern in Japanese provides a paradigm case for this scenario. As detailed in Itô \& Mester (1993), Japanese word-medial codas are filled either by the first half of a geminate or by a nasal which is homorganic with the following consonant, while word-final codas can only be filled by a placeless nasal, typically realised as a velar-like segment.

The point we want to make is that the cases in our database with only nasals in either word-medial or word-final codas, or in both, cannot be accounted for by placelessness. We focus here on word-final codas, because, as is evidenced in our database, place assimilation of nasals in medial codas is a fairly general phonological process, and as such not a reliable indicator of nasal placelessness. In the database there are nineteen languages with nasals in word-final codas, exhibiting a range of place specifications. Nine languages allow more than one place feature: $/ \mathrm{m} \mathrm{n} /$ occur in \|Ani, Chuave, Kapau and Khoekhoe, /m g/ in Idoma and Jul'hoan, and in Manam, where they are in free variation, /n y/ in Kela and all three places, $/ \mathrm{m} \mathrm{n} \mathrm{y} /$, in Gilbertese. In the remaining ten languages, word-final nasal codas have only one type of place, with uvular / $/$ occurring in Karen (Pwo), /m/ in Anufo, Ikwere, Kilivila, Naro and Sentani, and $/ \mathrm{y} /$ in Buin, Ndyuka, Qhalaxaryi and Wan. Of the nineteen cases with nasals as the only word-final coda consonants, fifteen cannot be accounted for under the placelessness scenario. While we could choose to account for the four remaining cases in terms of nasal placelessness, on the assumption that the segment transcribed as $/ \mathrm{y} /$ is indeed placeless rather than merely a velar (cf. Paradis \& Prunet 1990), this would lead to multiple partial explanations of the predominance of nasals as sole coda segments. Moreover, in the five languages that allow both nasals and glottals in word-final codas, the place of the coda nasal is velar in Macushi and Shanghai, coronal in Boiken and alternating between coronal and velar in Burmese and Panare. Again, placelessness can account for only some of the cases in this class documented in our database. As shown in Fig. 4 above, nasals also predominate as the only consonantal 
nuclei, yet no place-related perspective can be invoked in this case. In sum, if we invoke the placelessness scenario, we would not have a unified explanation for the general behaviour of nasals in syllable phonotactics. While some aspects of nasal phonotactics could be attributed to their potential placelessness, we view their overall behaviour in syllable phonotactics, including their privileged occurrence in both nuclei and codas, as driven primarily by their specific manner of articulation.

\section{Phonetic correlates of high- and low-sonority nasals}

We have proposed distinct representations for high- and low-sonority nasals. However, in our case studies we encounter a range of phonetic realisations of these two segment types, as schematised in Table IV. These realisations depend on the prosodification of the nasal as an onset, a coda or a nucleus, and on language-specific phonetics-phonology mappings. Crucial here is the [continuant] feature (see \$2.3). Segments with extreme velum lowering or incomplete oral closure are phonetic realisations of [nasal] without a [-continuant] specification, and are expected to occur in rhymal (coda or nucleus) position. While a prenasalised stop is phonologically specified as [-continuant], a phonetically plain nasal could have either phonological specification. Ramsammy (2012) found that Spanish postvocalic nasals display full oral occlusion when followed by stops, and incomplete occlusion when followed by continuants, corroborating our claim that nasals differ according to environment. Moreover, syllable-final nasals have a lower velum and longer velum lowering than syllable-initial nasals (Byrd et al. 2009 and references therein). Whether a positional or contrastive phonological specification of [-continuant] in nasals is realised as a perceptible stop gesture, or whether this gesture is completely masked by the lowering of the velum, depends on the phonology-phonetics interface of the system in which this happens. In Table IV, these different phonetic choices are mapped to their potential prosodic locations and their phonological specification.

\begin{tabular}{|c|c|c|c|c|c|}
\hline features & \multicolumn{2}{|c|}{$[$ nas, -cont $]$} & \multicolumn{3}{|c|}{ [nas] } \\
\hline phonetics & ${ }^{\mathrm{N}} \mathrm{P}$ & $\mathrm{N}$ & $\mathrm{N}_{\mathrm{T}}$ & $\tilde{\mathrm{G}}$ & $\tilde{\partial}$ \\
\hline \multirow{2}{*}{ prosody } & \multirow{2}{*}{\multicolumn{2}{|c|}{ onset }} & eus/ & & nucleus \\
\hline & & & \multicolumn{2}{|c|}{ rhyme } & \\
\hline
\end{tabular}

Table IV

Phonological, phonetic and prosodic mappings for nasals:

${ }^{\mathrm{N}} \mathrm{P}=$ prenasalised stop; $\mathrm{N}=$ plain nasal; $\mathrm{N}=$ nasal with extreme velar lowering; $\tilde{\mathrm{G}}=$ nasal glide; $\tilde{\text { a }}=$ schwa-like nasal. 
The relation between voiced stops, prenasalised stops and nasals warrants further discussion. Nasals alternate with voiced stops both synchronically and diachronically. Rice $(1989,1993)$ notes the variable realisation of Proto-Athabaskan *n as [d], [n] or [ $\left.{ }^{\mathrm{n}} \mathrm{d}\right]$ in the same position in some Slave dialects. In Lushootseed, nasals were reanalysed historically as voiced stops (see §2.2). The opposite transition, from voiced stops to prenasalised stops, has been noted in Mixtec (Iverson \& Salmons 1996), Greek (Arvaniti \& Joseph 2000) and Crow (Golston 2015), with prenasalisation analysed as hypervoicing. This is justified on physiological grounds. Henton et al. (1992) assume that prenasalisation is an articulatory strategy to facilitate voicing in stops. Vocal fold vibration needs airflow, which requires lower pressure above the larynx than below. Since pressure quickly increases in the oral cavity above the larynx, due to the outflowing air, voicing is difficult to maintain. One way of maintaining the pressure asymmetry above and below the larynx in order to sustain vocal fold vibration is to decrease supralaryngeal pressure by lowering the velum and letting excess air escape through the nasal cavity. Thus, diachronically, prenasalised voiced stops can be reanalysed as low-sonority nasals, and low-sonority nasals as prenasalised voiced stops.

\section{Conclusions}

In this paper we have examined the behaviour of nasal consonants in syllable phonotactics in a database of over 200 languages. From a perspective in which the sonority hierarchy is assumed to be central in the organisation of syllables, the findings we have presented are surprising. While we found patterns that support the traditional classification of nasals as being intermediate between obstruents and liquids on the sonority scale, we also presented converging evidence for locating nasals higher on the hierarchy, above liquids. We addressed this potential paradox by proposing that nasals occupy not one, but two, positions on the sonority hierarchy. We then elaborated a broad typology, dividing languages into those with only one type of nasal active in their phonological systems and those with both types. With this additional category in the sonority hierarchy and its language-specific distributional options, we account for the initially surprising prevalence of nasals in codas and nuclei. This amendment retains the spirit of Clements' (1990) Sonority Sequencing Principle, while considerably improving its empirical coverage.

We analysed these effects with the help of the feature [continuant]. In some languages, nasals are specified for this feature across the board, and in others only in certain prosodic positions, or not at all. Thus sonority effects, as well as apparent sonority paradoxes, are attributed in our analysis to the presence or absence of a specification for the feature [continuant]. The sonority hierarchy has been decomposed into features by a number of scholars (e.g. Basbøll 1977, Lekach 1979, Clements 1990, Giegerich 1992, de Lacy 2006). Our study contributes to the growing 
amount of evidence and analyses that improve our understanding of sonority effects as a correlate of categorical aspects of phonological representations and the constraints on these representations.

\section{REFERENCES}

Arvaniti, Amalia \& Brian D. Joseph (2000). Variation in voiced stop prenazalization in Greek. Glossologia 11-12. 131-166.

Baertsch, Karen (2002). An optimality theoretic approach to syllable structure: the split margin hierarchy. $\mathrm{PhD}$ dissertation, Indiana University.

Basbøll, Hans (1977). The structure of the syllable and proposed hierarchy of phonological features. In Wolfgang U. Dressler \& Oskar E. Pfeiffer (eds.) Phonologica 1976. Innsbruck: Innsbrucker Beiträge zur Sprachwissenchaft. 143-148.

Bell, Alan (1978). Syllabic consonants. In Greenberg et al. (1978). 153-201.

Berent, Iris, Donca Steriade, Tracy Lennertz \& Vered Vaknin (2007). What we know about what we have never heard: evidence from perceptual illusions. Cognition 104. 591-630.

Bethin, Christina Y. (1988). Polish nasal vowels. International Fournal of Slavic Linguistics and Poetics 38. 33-71.

Bethin, Christina Y. (1992). Polish syllables: the role of prosody in phonology and morphology. Columbus: Slavica.

Blevins, Juliette \& Sheldon P. Harrison (1999). Trimoraic feet in Gilbertese. Oceanic Linguistics 38. 203-230.

Bloomfield, Leonard (1933). Language. New York: Holt.

Botma, Bert (2004). Phonological aspects of nasality: an element-based dependency approach. PhD dissertation, University of Amsterdam.

Byrd, Dani, Stephen Tobin, Erik Bresch \& Shrikanth Narayanan (2009). Timing effects of syllable structure and stress on nasals: a real-time MRI examination. FPh 37. 97-110.

Clements, G. N. (1990). The role of the sonority cycle in core syllabification. In John Kingston \& Mary E. Beckman (eds.) Papers in laboratory phonology I: between the grammar and physics of speech. Cambridge: Cambridge University Press. 283-333.

Clements, G. N. \& Samuel J. Keyser (1983). CV phonology: a generative theory of the syllable. Cambridge, Mass.: MIT Press.

Clements, G. N. \& Sylvester Osu (2002). Explosives, implosives, and nonexplosives: the phonological function of air pressure differences in stops. In Carlos Gussenhoven \& Natasha Warner (eds.) Laboratory phonology 7. Berlin: Mouton de Gruyter. 299-350.

Clements, G. N. \& Sylvester Osu (2005). Nasal harmony in Ikwere, a language with no phonemic nasal consonants. Fournal of African Languages and Linguistics 26. 165-200.

Cohn, Abigail (1993). The status of nasalized continuants. In Marie K. Huffman \& Rena A. Krakow (eds.) Nasals, nasalization, and the velum. Orlando: Academic Press. 329-367.

Cooper, Adam I. (2013). The typology of PIE syllabic sonorants. Indo-European Linguistics 1. 3-67.

Cowan, H. K. J. (1965). Grammar of the Sentani language (with specimen texts and vocabulary). The Hague: Martinus Nijhoff.

de Lacy, Paul (2006). Markedness : reduction and preservation in phonology. Cambridge: Cambridge University Press.

Dell, François \& Mohamed Elmedlaoui (1985). Syllabic consonants and syllabification in Imdlawn Tashlhiyt Berber. Fournal of African Languages and Linguistics 7. 105-130. 
Dell, François \& Mohamed Elmedlaoui (1988). Syllabic consonants in Berber: some new evidence. Fournal of African Languages and Linguistics 10. 1-17.

Dryer, Matthew S. \& Martin Haspelmath (eds.) (2013). The world atlas of language structures online. Leipzig: Max Planck Institute for Evolutionary Anthropology. Munich: Max Planck Digital Library. Available (January 2020) at http://wals.info.

Durvasula, Karthik (2009). Understanding nasality. PhD thesis, University of Delaware.

Firchow, Irwin \& Jacqueline Firchow (1969). An abbreviated phoneme inventory. Anthropological Linguistics 11. 271-276.

Foley, William A. (1986). The Papuan languages of New Guinea. Cambridge: Cambridge University Press.

Giegerich, Heinz J. (1992). English phonology: an introduction. Cambridge: Cambridge University Press.

Golston, Chris (2015). Hypervoicing in Crow. Poster presented at the 2015 Annual Meeting on Phonology, University of British Columbia.

Gordon, Matthew K. (2016). Phonological typology. Oxford: Oxford University Press.

Greenberg, Joseph H. (1978). Some generalizations concerning initial and final consonant clusters. In Greenberg et al. (1978). 243-279.

Greenberg, Joseph H., Charles A. Ferguson \& Edith A. Moravcsik (eds.) (1978) Universals of human language. Vol. 2: Phonology. Stanford: Stanford University Press.

Groves, Terab'ata R., Gordon W. Groves \& Roderick Jacobs (1985). Kiribatese: an outline description. Canberra: Australian National University.

Gudschinsky, Sarah C., Harold Popovich \& Frances Popovich (1970). Native reaction and phonetic similarity in Maxakalí phonology. Lg 46. 77-88.

Gussmann, Edmund (2007). The phonology of Polish. Oxford: Oxford University Press.

Hankamer, Jorge \& Judith Aissen (1974). The sonority hierarchy. In Anthony Bruck, Robert Fox \& Michael La Galy (eds.) Papers from the parasession on natural phonology. Chicago: Chicago Linguistic Society. 131-145.

Hayes, Bruce (1995). Metrical stress theory: principles and case studies. Chicago: University of Chicago Press.

Heffner, R.-M. S (1950). General phonetics. Madison: University of Wisconsin Press.

Henton, Caroline, Peter Ladefoged \& Ian Maddieson (1992). Stops in the world's languages. Phonetica 49. 65-101.

Hess, Thom (1982). Traces of 'abnormal' speech in Lushootseed. Working Papers for the 17th International Conference on Salish and Neighboring Languages. 89-97.

Hooper, Joan B. (1976). An introduction to natural generative phonology. New York: Academic Press.

Hyman, Larry M. \& Armindo Ngunga (1997). Two kinds of moraic nasal in Ciyao. Studies in African Linguistics 26. 131-163.

Itô, Junko (1986). Syllable theory in prosodic phonology. PhD dissertation, University of Massachusetts, Amherst. Published 1988, New York: Garland.

Itô, Junko (1989). A prosodic theory of epenthesis. NLLT 7. 217-259.

Itô, Junko \& Armin Mester (1993). Licensed segments and safe paths. Canadian Fournal of Linguistics 38. 197-213.

Iverson, Gregory K. \& Joseph C. Salmons (1996). Mixtec prenasalization as hypervoicing. IFAL 62. 165-175.

Jespersen, Otto (1904). Lehrbuch der Phonetik. Leipzig \& Berlin: Teubner.

Keegan, John M. (1997). A reference grammar of Mbay. Munich: Lincom.

Kenstowicz, Michael \& Jerzy Rubach (1987). The phonology of syllabic nuclei in Slovak. $\operatorname{Lg}$ 63. 463-497.

Kinkade, M. Dale (1985). More on nasal loss on the Northwest coast. IFAL $\mathbf{5 1 .}$ 478-480.

Kiparsky, Paul (1979). Metrical structure assignment is cyclic. LI 10. 421-441. 


\section{Martin Krämer and Draga Zec}

Krämer, Martin (2003). What is wrong with the right side? Edge (a)symmetries in phonology and morphology. Ms, University of Ulster. Available as ROA-576 from the Rutgers Optimality Archive.

Ladefoged, Peter \& Ian Maddieson (1996). The sounds of the world's languages. Oxford \& Malden, Mass.: Blackwell.

Lekach, A. F. (1979). Phonological markedness and the sonority hierarchy. MIT Working Papers in Linguistics 1. 172-177.

Levin, Juliette (1985). A metrical theory of syllabicity. PhD dissertation, MIT.

Lichtenberk, Frantisek (1983). A grammar of Manam. Honolulu: University of Hawaii Press.

Mielke, Jeff (2005). Ambivalence and ambiguity in laterals and nasals. Phonology 22. 169-203.

Mielke, Jeff (2008). The emergence of distinctive features. Oxford: Oxford University Press.

Morén, Bruce (1999). Distinctiveness, coercion and sonority: a unified theory of weight. $\mathrm{PhD}$ dissertation, University of Maryland, College Park.

Ngunga, Armindo (2000). Phonology and morphology of the Ciyao verb. Stanford: CSLI.

Ohala, John J. (1975). Phonetic explanations for nasal sound patterns. In Charles A. Ferguson, Larry M. Hyman \& John J. Ohala (eds.) Nasálfest: papers from a symposium on nasals and nasalization. Stanford: Language Universals Project Stanford University. 289-316.

Padgett, Jaye (1991). Stricture in feature geometry. $\mathrm{PhD}$ dissertation, University of Massachusetts, Amherst.

Paradis, Carole \& Jean-François Prunet (1990). Coronal or velar placeless consonants? WCCFL 9. 427-441.

Paradis, Carole \& Jean-François Prunet (2000). Nasal vowels as two segments: evidence from borrowings. $\operatorname{Lg}$ 76. 324-357.

Parker, Stephen G. (2002). Quantifying the sonority hierarchy. PhD dissertation, University of Massachusetts, Amherst.

Piggott, Glyne L. (1992). Variability in feature dependency: the case of nasal harmony. NLLT 10. 33-77.

Piggott, Glyne L. (1999). At the right edge of words. The Linguistic Review 16. 143-185.

Prince, Alan \& Paul Smolensky (1993). Optimality Theory: constraint interaction in generative grammar. Ms, Rutgers University \& University of Colorado, Boulder. Published 2004, Malden, Mass. \& Oxford: Blackwell.

Ramsammy, Michael (2012). The realisation of coda nasals in Spanish. $\mathrm{PhD}$ thesis, University of Manchester.

Ravenhill, Philip L. (1982). The Wan language. Bulletin semestriel d'études linguistiques mandé 4. 57-69.

Rice, Keren (1989). A grammar of Slave. Berlin \& New York: Mouton de Gruyter.

Rice, Keren (1993). A reexamination of the feature [sonorant]: the status of 'sonorant obstruents'. $L g$ 69. 308-344.

Rice, Keren \& Peter Avery (1989). On the interaction between sonorancy and voicing. Toronto Working Papers in Linguistics 10. 65-82.

Ridouane, Rachid (2008). Syllables without vowels: phonetic and phonological evidence from Tashlhiyt Berber. Phonology 25. 321-359.

Riehl, Anastasia K. (2008). The phonology and phonetics of nasal obstruent sequences. $\mathrm{PhD}$ dissertation, Cornell University.

Robinson, Stuart (2006). The phoneme inventory of the Alta dialect of Rotokas. Oceanic Linguistics 45. 206-209.

Rose, Sharon (2000). Epenthesis positioning and syllable contact in Chaha. Phonology 17. $397-425$. 
Saussure, Ferdinand de (1916). Cours de linguistique générale. Lausanne \& Paris: Payot. Scatton, Ernest A. (1984). A reference grammar of Modern Bulgarian. Columbus: Slavica.

Schütz, Albert J. (1985). The Fijian language. Honolulu: University of Hawaii Press.

Selkirk, Elisabeth (1982). The syllable. In Harry van der Hulst \& Norval Smith (eds.) The structure of phonological representations. Part 2. Dordrecht: Foris. 337-383.

Selkirk, Elisabeth (1984). On the major class features and syllable theory. In Mark Aronoff \& Richard T. Oerhle (eds.) Language sound structure. Cambridge, Mass.: MIT Press. 107-136.

Shosted, Ryan K. (2006). The aeroacoustics of nasalized fricatives. PhD dissertation, University of California, Berkeley.

Sievers, Eduard (1881). Grundzüge der Phonetik. Leipzig: Breitkopf \& Härtel.

Smith, Jennifer L. (2007). Representational complexity in syllable structure and its consequences for GEN and CoN. In Sylvia Blaho, Patrik Bye \& Martin Krämer (eds.) Freedom of analysis? Berlin \& New York: Mouton de Gruyter. 257-280.

Steriade, Donca (1982). Greek prosodies and the nature of syllabification. $\mathrm{PhD}$ dissertation, MIT.

Trigo, Loren (1988). The phonological derivation and behavior of nasal glides. $\mathrm{PhD}$ dissertation, MIT.

Trigo, Loren (1993). The inherent structure of nasal segments. In Marie K. Huffman \& Rena A. Krakow (eds.) Nasals, nasalization, and the velum. Orlando: Academic Press. 369-400.

Urbanczyk, Suzanne (2001). Patterns of reduplication in Lushootseed. New York: Garland.

Vennemann, Theo (1972). On the theory of syllabic phonology. Linguistische Berichte 18. 1-18.

Vries, Lourens de \& Robinia de Vries-Wiersma (1992). The morphology of Wambon of the Irian Faya Upper-Digul area: with an introduction to its phonology. Leiden: KITLV Press.

Wiese, Richard (2001). The phonology of /r/. In T. Alan Hall (ed.) Distinctive feature theory. Berlin \& New York: Mouton de Gruyter. 335-368.

Wiese, Richard (2003). The unity and variation of (German) /r/. Zeitschrift für Dialektologie und Linguistik 70. 25-43.

Yip, Moira (2011). Lateral consonants. In Marc van Oostendorp, Colin J. Ewen, Elizabeth Hume \& Keren Rice (eds.) The Blackwell companion to phonology. Malden, Mass.: Wiley-Blackwell. 730-754.

Zaleska, Joanna \& Andrew Nevins (2015). Transformational language games and the representation of Polish nasal vowels. NELS 45. 251-260.

Zec, Draga (1988). Sonority constraints on prosodic structure. PhD dissertation, Stanford University.

Zec, Draga (1995). Sonority constraints on syllable structure. Phonology 12. 85-129.

Zec, Draga (2007). The syllable. In Paul de Lacy (ed.) The Cambridge handbook of phonology. Cambridge: Cambridge University Press. 161-194.

Zec, Draga (2013). Liquid syllable nuclei in Slavic: consonantal or vocalic? In Steven Franks, Markus Dickinson, George Fowler, Melissa Witcombe \& Ksenia Zanon (eds.) Formal approaches to Slavic linguistics: the 3rd Indiana meeting 2012. Ann Arbor: Michigan Slavic Publications. 436-450. 